\title{
Group status, minorities and trust
}

\author{
Kei Tsutsui • Daniel John Zizzo
}

Received: 19 May 2012 / Accepted: 29 April 2013 / Published online: 11 May 2013

(C) The Author(s) 2013. This article is published with open access at Springerlink.com

\begin{abstract}
We present the results of an experiment measuring the impact of low group status and relative group size on trust, trustworthiness and discrimination. Subjects interact with insiders and outsiders in trust games and periodically enter markets where they can trade group membership. Low status and minority subjects have low morale: that is, they comparatively dislike being low status and being minority subjects. Group discrimination against low status and minority subjects is unchanged. However, low status subjects are deferential to high status subjects in terms of comparatively higher trust, and minority subjects are deferential to majority subjects in terms of comparatively higher trustworthiness.
\end{abstract}

Keywords Groups · Trust games · Deference · Discrimination · Status · Group size

JEL Classification $\mathrm{C} 72 \cdot \mathrm{C} 91 \cdot \mathrm{Z} 13$

\section{Introduction}

In recent years there has been an increasing attention to the importance of groups in understanding and explaining social capital, cooperation and well-being. For example, there is some evidence that membership in a group can affect subjects' behavior in prisoner's dilemma and battle of the sexes games (Charness et al. 2007;

Electronic supplementary material The online version of this article

(doi:10.1007/s10683-013-9364-x) contains supplementary material, which is available to authorized users.

K. Tsutsui

Frankfurt School of Finance and Management, Frankfurt am Main, Germany

D.J. Zizzo (凶)

CBESS and School of Economics, University of East Anglia, Norwich NR4 7TJ, UK

e-mail:d.zizzo@uea.ac.uk 
Goette et al. 2006), in the public goods game (e.g., Tan and Bolle 2007), in bargaining settings (Hargreaves Heap and Varoufakis 2002; Zizzo 2003), two person sequential games (Chen and Li 2009), trust games (Hargreaves Heap and Zizzo 2009) and in coordination games (Chen and Chen 2010). Intergroup bias forms naturally already with children (e.g., Sherif 1967; Files et al. 2010), and group identification has been hypothesized to be a source of individual well-being (e.g., Akerlof and Kranton 2002); indeed, there is some neurobiological evidence that being a member of a group produces an endorphin rush (see Dunbar 2006).

The starting point of this paper is that, almost pervasively, groups come in different relative sizes and/or social status. When there is discussion of ethnic conflict, for example, this is often phrased along the lines of majorities and minorities. ${ }^{1}$ Similarly, perceptions of different social status are often perceived to accompany members of different groups: ${ }^{2}$ for example, within an organization, members of a given team or of an 'old boys and/or girls network' being given status that other teams or those who are not in the elite network within the same organization do not have; or, more generally, Ivy League graduates vs. graduates from a local community college; or members of different castes in the traditional Hindu societal structure (BBC 2007). In some cases majority and minority status coincide with high and low status respectively: for example, domestic nationals versus perceived foreigners that are deemed of low status (e.g., Costello and Hodson 2011). Recent policy measures in both western Europe and United States have come under scrutiny for the extent to which they may hide, or institutionalize, intergroup discrimination by domestic nationals with respect to immigrant minorities made by foreign nationals. ${ }^{3}$ In Japan, the segregation between the ordinary citizens who belonged to four recognized ranks (samurai warriors; farmers; artisans and trade people) and the minority outsiders were institutionalized in the sixteenth century. The discrimination against the outcast group still exists nowadays (Sugimoto 2003).

A key step in trying to understand the implications of groups for economies and organizations is then to look at how changing relative group size and/or changing group status affects trust and trustworthiness: this is what we do in this paper. Social identity theory would predict that subjects' feelings of self-worth derive from

\footnotetext{
${ }^{1}$ For example, Hutu majority and Tutsi minority in Burundi and Rwanda; Sinhalese majority and Tamil minority in Sri Lanka; the French majority and Roma minority in France; the national ethnic majority and the Jewish minority at various times of European history, such as 16th century Spain or Nazi Germany; the black majority and white minority in South Africa at the time of apartheid.

${ }^{2}$ Psychological theories that have tried to explain hierarchical group relationships are social identity theory (Tajfel and Turner 2001), where lower status groups contribute less to individual social identity therefore leading to differential attitudes; social dominance theory (Sidanius and Pratto 1999), which posits that low status group exhibit less ingroup bias insofar as they see the status differential as legitimate; and system justification theory (Jost and Banaji 1994), in which low status subjects are seen as internalizing beliefs that serve to maintain the status quo, even when detrimental to themselves.

${ }^{3}$ Three recent examples are the new controversial anti-immigration policy in Arizona, which is being legally challenged by the Obama administration (Montopoli 2010); the recent waves of anti-Roma raids in France (Brooks 2010); and the curious way in which the U.K. the increase in high fee paying international student numbers is seen as a problem requiring a tightening in immigration policy (Mulholland 2010), at a time in which heavy public funding cuts and broader economic fragility should imply a greater rather than lower need for the income that these students bring.
} 
being member of a group; low status group membership (or minority group membership insofar as it is perceived as low status) may be associated to lower selfevaluation (and hence psychological value) and to coping strategies that may include deferential behavior towards the high status (or majority) group (e.g. Turner 1975; Tajfel and Turner 2001). There is suggestive evidence that this is the case (e.g., Milner 1975), but equally perceptions of minorities as low status may change as minorities develop better self-identities, e.g. with African Americans (Harris and Brown 1971), making interpretation difficult. In empirical work respectively with U.S. and Indian data, Alesina et al. (1999) and Banerjee et al. (2005) show that social fragmentation can be negative for public good provision. One specific problem of interpretation is the extent to which though there is a causal link between social fragmentation and social welfare. There is also a question of how, for specific natural groups, results may depend on specific sets of stereotypes associated to the natural groups rather than apparent inter-group preferences, as Fershtman and Gneezy (2001) find in relation to the separation between Ashkenazic Jews and Eastern Jews (though with males only). ${ }^{4}$ They may also depend on group-specific social norms (Berger et al. 2011) and preferences (Fehr et al. 2008). An experiment with artificial groups can then be ideally placed to identify the causal effect of having minority and low status groups independently of looking at the effect of the stereotypes, social norms and preferences associated to specific natural groups.

We do so such an experiment in the context of trust games, which is a natural stylized modeling setup for the operation of social capital. For example, in an organizational context, and as noted by Johnson and Mislin (2008), trust is recognized to raise efficiency by lower monitoring costs and turnover and by increasing uncompensated positive behavior from employees. These are normally seen as working in the direction of what Hargreaves Heap and Zizzo (2009; HHZ in what follows) label positive discrimination: i.e. greater trust and trustworthiness than what would be expected if there were no partitions of agents into groups. ${ }^{5}$ There could also however be what HHZ label negative discrimination: i.e. lower trust and trustworthiness than what would be expected if there were no partitions of agents into groups. HHZ found evidence of negative discrimination in their trust game experiment, which suggests that the relationship between groups and social capital may be more complex than usually posited, at least in trust settings. ${ }^{6}$

\footnotetext{
${ }^{4}$ Goette et al. $(2006,2012)$ find evidence of discrimination in a field experiment with Swiss Army platoons, but do not look at issues of minority groups of status.

${ }^{5}$ One can always label the set of all subjects as a group, and so in a sense one could rephrase this as stating that the introduction of further sub-groups would lead to further trust and trustworthiness within the sub-group relative to the baseline in which no sub-group would exist. The same would be true in an experimental setting, i.e. all subjects in an experimental group could identify themselves as a single group in addition to any further group manipulation; but this does not prevent us from identifying experimentally the effects of having a further group manipulation, and this is what $\mathrm{HHZ}$ already do. As a result, we find it simpler to rely just on the standard terminology of talking of either partitioning subjects into groups or not having groups; and we follow others (such as Chen and Li 2009; Chen and Chen 2010 and HHZ) in doing so.
}

${ }^{6}$ Table 2 of Chen and Li (2009) shows evidence of positive discrimination but, arguably, stronger evidence of negative discrimination in their sequential bargaining games. The findings on negative discrimination stand in contrast with the emphasis by some on positive discrimination (e.g., Brewer 1999). 
Our focus is on a simple, financially incentivized, deception-free behavioral experiment that implements our experimental treatment manipulations in a minimal way. We differ from experimental psychology research looking at relative group size and status effects as the latter's focus is typically (a) on attitudes rather than behavior (e.g., Ellemers et al. 1992; Jost and Burgess 2000; Lücken and Simon 2005; Voci 2006); (b) when behavior is involved, deception is systematically used in invoking the connection between responses and behavior (e.g., Sachdev and Bourhis 1985, 1991); (c) deception is more generally and systematically employed in treatment manipulations and elsewhere in the experimental design (e.g., all the studies listed under parts a and b). This is not to say that this psychological research is not useful: it clearly is; our aim is simply to complement it using an experimental economic methodology. ${ }^{7}$ The early experimental research on in-group favoritism (e.g., Tajfel 1970) is also relevant but more distant from what we do, since it neither distinguishes between positive and negative discrimination nor does it look at issues of group size and status.

Experiments with natural groups are less likely to employ deception (e.g., Aberson and Howanski's, 2002, attitudinal study), but, as noted above, once natural groups as opposed to artificial groups are introduced, the question arises of disentangling what we might label as the 'pure' effect of group membership and intergroup relations from what may be, and often plausibly are, expectations and stereotyping effects at play (e.g., Arifovic et al. 2012; Liebkind et al. 2008). This is what makes employing artificial groups desirable in a first step to identify the pure causal impact of relative size and status.

Our experimental design benchmark is from HHZ. To identify relative group size effects, all we do, relative to the random color group assignment treatment of HHZ, is to vary the group size from the two HHZ groups of 6 subjects each to having one group of 8 subjects and one group of 4 subjects. ${ }^{8}$ We control for absolute group size effects by also having control treatments in which we either pair two groups of 4 subjects each or we pair two groups of 8 subjects each. ${ }^{9}$ To identify status effects, all we do is to change the labeling frame we adopt in experimental sessions: rather than talking of a Blue group and a Red group (as we do in the other treatments, finding symmetrical results as HHZ do), we phrase the instructions in terms of a Blue group and in terms of subjects who are "not belonging to any group" or "outsiders to the group". This is a minimal status group manipulation: that of being in a first group and that of being in a second group which is defined purely negatively by not being a member of the first group. Such a minimal status group manipulation arguably has the advantage of improving the interpretability of the results relative to stronger manipulations based on entitlements inducing quizzes and/or a public

\footnotetext{
${ }^{7}$ Glaeser et al. (2000) and Fehr et al. (2003) look at the relationship between survey responses and experimental behavior.

${ }^{8}$ We rely on random matching so that each player has equal probability to play with any other player in the laboratory. Section 4 contains a further discussion.

${ }^{9}$ Larger majorities and smaller minorities are of course of interest for future research, but they are not suitable for a first study since, because of the random matching mechanism needed (see previous footnote), it would reduce considerably the amount of data from insider-outsider interaction, and the likelihood to have the power to detect intergroup discrimination in the lab.
} 
ceremony at the end of the experiment. Deservingness perceptions — as induced by quizzes - is an alternative obvious source of differential behavior (e.g., Hoffman and Spitzer 1985), and public ceremonies may increase the likelihood of experimenter demand effects driving the results. The subtlety of our cue helps reduce the likelihood of experimenter demand effects; we use a variant of a Holt and Laury (2002) task as an extra control for whether such effects drive our results, and we find that they do not. ${ }^{10}$ It also has external validity. This is because it mirrors the way in which sometimes low status is associated to being perceived as being outsiders to the high status groups, as the buraku are relative to the four recognized ranks of traditional Japanese society (Sugimoto, 2003).

To give a preview of key findings, there is evidence of comparatively low morale associated to low status and minority subjects. There is also evidence of deference, in different ways, towards high status and majority subjects respectively. The rest of this paper is organized as follows. Sections 2 and 3 present the experimental design and results, respectively. Section 4 discusses the results, while Sect. 5 concludes.

\section{Experimental design}

\subsection{Outline and stage 1}

The experiment was conducted in January and February 2010 at the University of East Anglia. ${ }^{11}$ Other than for the experimental instructions, the experiment was computerized using the software z-Tree platform (Fischbacher 2007). Subjects were mostly students from various subject backgrounds. A total of 312 subjects participated in the 26 sessions. Subjects were randomly seated in the laboratory in partitioned computer terminals. Subjects read the instructions and answered a computerized control questionnaire, to check understanding, before moving on with the tasks. They were advised individually if they gave any incorrect answers. The experimental instructions had a neutral frame (e.g., did not refer to 'trust', 'trusters' or 'trustees') except for the context manipulations specified below. We used 'experimental points' as currency, each worth 4 UK pence ( 0.04 pounds).

We had three key experimental treatments, each with two groups per session: two groups frame, one with a majority of 8 subjects and the other with a minority of 4 subjects (84); one group frame, with the majority group of 8 being labeled as 'the group' engaging with 4 outsiders (S4); one group frame, with the minority group of 4 being labeled as 'the group' engaging with 8 outsiders $(S 8)$. As controls for the analysis, we also ran two additional treatments: two groups frame of 8 subjects (88); two groups frame of 4 subjects (44); and we also relied on the no groups $(B)$ and the two groups of 6 subjects each with equal frequencies to play with the same and other group members (66) treatments reported in HHZ. ${ }^{12}$

\footnotetext{
${ }^{10}$ See Zizzo (2010) for a discussion of experimenter demand effects. Section 4 contains a further discussion of our status manipulation.

${ }^{11}$ The experimental instructions are provided at http://www.uea.ac.uk/ ec601/MinExpEAppendix2.pdf.

$12 B$ had 5 sessions and 66 had 4 sessions, implying a total of an additional $9 \times 12=108$ subjects for the data analysis. 66 is labeled as $\mathrm{C}$ treatment in HHZ; we have changed the labeling to make it more congruent
} 
At the start of the experiment subjects were randomly assigned to one of two groups, to be made of either 4 or 8 subjects depending on the treatment, and this was common knowledge. In two groups frame treatments, the groups were labeled the Red group and the Blue group. ${ }^{13}$ In the one group frame treatments, there are a Blue group and four or eight Not Blue subjects (depending on the treatment) who in the instructions are referred to as "not belonging to any group" or "outsiders to the group".

Our key experimental treatments are those looking at majorities, minorities and difference in status: $84, S 4$ and $S 8.84$ considers the effect of having a majority and a minority framed as providing two group identities of equal status except for the potential implications of being a majority group or a minority group. $S 4$ and $S 8$ consider the effect of differential status by having a single group labeled as such, as discussed in the introduction and further in Sect. 4. In $S 4$, the majority group of 8 is the high status (Blue), framed group and the group of 4 is the unlabeled, low status group (Not Blue); in $S 8$, the minority group of 4 is the high status, framed group and the group of 8 is the low status group.

Any difference in behavior from being in the majority or in the minority may however not be due to any majority-minority effect (whether or not combined with a 1 group frame effect) but rather to the absolute size of the group (4 or 8 subjects). In 44 and 88 there are no majorities and minorities, but by having groups of 4 (in 44) and of 8 (in 88) we are able to control for absolute group size effects. 44 and 88 do however change the absolute number of people participating to each experimental session (8 and 16, respectively, relative to the 12 of the other treatments), and to control for this as well we can employ the experimental data from 66 in HHZ. Finally, there is a question about what would happen if there were no groups, and the $B$ treatment from $\mathrm{HHZ}$ provides such a useful baseline.

Each session was divided into four stages plus four additional behavioral tasks, and the overall experimental sequence and set of treatments is summarized in Table 1.

\subsection{Stage 1}

Stage 1 had three rounds of a Berg et al. (1995) basic trust game and was common to all treatments. It aimed to provide subjects practice and experience with trust games. The truster (the 'First Mover') received 24 experimental points and chose how many points (if any) to give to the other person and how many (if any) to keep. All the points given were multiplied by a conversion rate of 3 before they were received by the trustee (the 'Second Mover'). The trustee then decided how much (if any) to keep and how much (if any) to return to the truster. Subjects were matched randomly

with that of our experimental treatments. Using two treatments from $\mathrm{HHZ}$ as baselines is especially useful as the subject samples were comparable, as (a) they were run in the same university and so with the same kind of subject pool and (b) the same experimenter (namely, the first author of this paper) materially conducted both our experimental sessions and those reported in HHZ.

${ }^{13}$ In treatment 84 , three sessions were run with the Red group as the majority group and three with the Blue group as the majority group. Hence the numbers subjects in the Red and Blue are the same in the all two frame treatments. 
Table 1 Experimental treatments and experimental sequence

\begin{tabular}{|c|c|c|c|c|c|}
\hline \multirow[t]{2}{*}{ Treatment } & \multicolumn{2}{|c|}{ Two frames } & \multicolumn{2}{|c|}{ One frame } & \multirow[t]{2}{*}{ No frame } \\
\hline & Blue & Red & Blue & Not Blue & \\
\hline \multicolumn{6}{|c|}{ Main treatments } \\
\hline 84 & $8(4)$ & $4(8)$ & & & \\
\hline$S 4$ & & & 8 & 4 & \\
\hline$S 8$ & & & 4 & 8 & \\
\hline \multicolumn{6}{|c|}{ Control treatments } \\
\hline$B$ & & & & & 12 \\
\hline 66 & 6 & 6 & & & \\
\hline 44 & 4 & 4 & & & \\
\hline 88 & 8 & 8 & & & \\
\hline \multicolumn{2}{|c|}{ Experimental sequence } & \multicolumn{3}{|l|}{ Task } & Number of rounds \\
\hline \multicolumn{2}{|l|}{ Stage 1} & \multicolumn{3}{|l|}{ Trust games } & 3 \\
\hline \multicolumn{2}{|l|}{ Stage 2} & \multicolumn{3}{|c|}{ Market 1 or Waiting Period 1 , trust games } & 6 \\
\hline \multicolumn{2}{|l|}{ Stage 3} & \multicolumn{3}{|c|}{ Market 2 or Waiting Period 2, trust games } & 6 \\
\hline \multicolumn{2}{|l|}{ Stage 4} & \multicolumn{3}{|c|}{ Market 3 or Waiting Period 3 , trust games } & 6 \\
\hline
\end{tabular}

Notes: In the top two panels, the number of subjects in each group (or everyone in the experimental session, for the $B$ treatment) is listed (in the 84 treatment, either the Blue group has 8 subjects and the Red group 4 subjects, or vice versa). Regarding the bottom panel, at the start of each of stages 2,3 , and 4 , the experiment had a waiting period in the $B$ treatment, and markets for group(s) in the $66,88,44,84, S 8$ and $S 4$ treatments (technically, there were two markets, one to pay for membership of each of the two groups)

and anonymously each round. ${ }^{14}$ The only information they received was about their round co-player's decision and about their own round earnings; in treatments with groups, they had no information about the color group of co-players.

\subsection{Stages 2 through 4}

Trust games In stages 2, 3 and 4 subjects played six trust games as in stage 1, but with the following differences. Each round trusters were allocated 48 points rather than the 24 of stage 1 . In each round they were randomly matched with another participant in the room, and informed whether the co-player belonged to the Blue group or to the Red group or to no group, though they were not told their identity. They were assigned three times the role of trusters and three times that of trustees. They were provided, on a round-by-round basis, with a table containing information on average giving rates and average return rates by members of each group (or "not

\footnotetext{
${ }^{14}$ They were asked to make decisions within 1 minute and a half, and a small clock on the computer display informed them of how much time they had. In practice, however, they could take more, though they rarely did.
} 
belonging to any group") with respect to insiders and outsiders. ${ }^{15}$ In addition, they received a summary table with average giving and return rates for each stage from the second onwards by members of each group with respect to insiders and outsiders.

Market for groups phase Before stages 2, 3 and 4 of the trust games were played, there was a market for groups as in HHZ. Subjects had an endowment of 48 points. In the two groups frame treatments, they were first asked to state whether, if they could choose and both options were free, they would rather stay in their group or switch to the other. If he or she stated they would rather switch, then they became a potential buyer for the membership of the other group and they were asked how much they were willing to pay to swap places with a member of the other group. They could state any value between 0 and 48 points, the value of their endowment. If the subjects stated they would rather stay, they became a potential seller of group membership and were asked to state how much they would need to be paid by a member of the other group in order to swap places, again with an upper limit of 48 points. Subjects could also state that they were not willing to switch group at any price within the allowed range ( 0 to 48 points).

The one group frame treatments were identical in structure but the instructions were framed in terms of being in or out of the Blue group. For all treatments, the market then operated as a Walrasian clearinghouse, where the price was set so that the number of sellers was equal to the number of buyers of membership of the other group. Whenever there was a range of possible market-clearing prices, the lowest market-clearing price was chosen. As in HHZ, the mechanism only operated by swapping players between groups, so that each group remained with the same number of subjects throughout the experiment. ${ }^{16}$

\subsection{End of experiment tasks}

At the end of the experiment we had four behavioral tasks presented in randomized order and aimed to try to measure risk aversion, loss aversion, ambiguity aversion and sensitivity to experimenter demand. ${ }^{17}$ They corresponded to (a) a standard Holt and Laury (2002) questionnaire in the domain of gains; (b) an equivalent task in the domain of losses; (c) an ambiguity aversion task; and (d) a sensitivity to experimenter demand task. The tasks details are provided in the experimental instructions. The number of times subjects choose the safer option can be taken as a measure of risk attitude in task a. Task b consisted in a set of choices between risky options as in a, but framed in terms of losses rather than in gains; we combine task a choices of the safer option with task $b$ choices of the riskier option to get a proxy for degree of loss aversion. ${ }^{18}$ Task c followed the lead of Engle-Warnick and Laszlo (2006)

\footnotetext{
${ }^{15}$ We provided this information for comparability with Hargreaves Heap and Zizzo (2009). It enables us to enhance the scope for learning in repeated group interaction where subjects know how subjects are faring. As it could inadvertently set a norm or target amount of trust that the subjects might try to meet in later rounds, though, future research could consider giving subjects no or less feedback.

${ }^{16}$ Subjects were told that they should make their market decisions within four minutes.

${ }^{17}$ Due to a computer failure, we were not able to collect this data for one session of treatment 88 .

${ }^{18} \mathrm{~A}$ loss aversion subject would be risk loving in the domain of losses while being risk averse in the domain of gains.
} 
and offered a choice between an increasingly ambiguous lottery and the same lottery disambiguated but at a price in terms of lower expected value. The number of times subjects went for the unambiguous measure can be used as a measure of ambiguous aversion.

Task d presented an option between two lottery choices, one increasingly dominated by the other; the dominated option was characterized by a smiley face and a sentence stating that "it would be nice if some of you were to choose" such an option. The nudge provided towards choosing the dominated lotteries was significant by the standard of what we know about experimenter demand effects (see Zizzo 2010), abbreviated as EDE in what follows, with the smiley face providing a social cue to interpret the sentence being provided. It provided a clear cue for subjects to behave in a way compliant to experimenter demand, even when they need to pay money to do so, and as such it is a measure of sensitivity to EDE. ${ }^{19}$ It is not just a generic measure of conformism since the nudge clearly comes from the experimenter. As a result, we measure the degree of EDE sensitivity as the number of dominated options choices being made. Zizzo and Fleming (2011) used a psychological questionnaire instrument and a combination of a dictator and money burning game as alternative measures to capture EDE sensitivity; relative to the first measure, our Holt and Laury variant measure had the advantage of providing an incentivized measure; relative to the second measure, and given the interpersonal nature of our experiment and potential spillovers across tasks, it had the advantage of not involving actions affecting other subjects in the experiment.

\subsection{Payments}

Each session lasted around 75 minutes. The average earnings were 14.39 UK pounds per subject (approximately 22-23 US dollars). Payment was based on the earnings from each of the markets; plus those from a randomly chosen round from each of the four stages; plus those from one of the ten choices for each of the end of experiment tasks, with any relevant lottery being played out by the computer. Subjects were privately paid and left the laboratory one at a time in an order designed to minimize the likelihood of seeing each other.

\footnotetext{
${ }^{19} \mathrm{An}$ alternative interpretation of our behavioral measure is that it captures subjects being nice towards the experimenter as opposed to a form of experimenter demand effect. The problem with this argument is that being nice towards the experimenter could precisely be interpreted as a form of experimenter demand effect; while the argument that the manipulation simply captures subjects being nice, i.e. altruistic, does not explain why it does not correlate with greater average trust or trustworthiness. Furthermore, the fact that face based stimuli are sufficient to induce compliant behavior (e.g., Bateson et al. 2006; Burnham and Hare 2007; Haley and Fessler 2005) makes clear that such visual aids are effective in providing social meaning towards the choice of the dominated option. Note that we could not say that "it would be nice if all of you were to choose" the dominated option, since this sentence would in fact have been deceptive given our experimental goals (the usefulness of the measure is in having a distribution of subjects based on the measure).
} 


\subsection{Relationship to baseline treatments from $\mathrm{HHZ}$}

The 66 treatment was identical in stages 1 through 4 structure to that of our experimental treatments under a two groups frame, with the key difference being that there were two groups of six subjects. ${ }^{20}$

The $B$ treatment had 12 subjects per session as the $66,84, S 8$ and $S 4$ treatments. There was no assignment to groups. Stage 1 was identical to stage 1 of the other treatments. Stages 2, 3 and 4 had no market for groups. In its place, at the beginning of each of stages 2, 3 and 4, there was a two minutes waiting period, at the start of which subjects were paid an additional 48 points. This was meant to mirror the other treatments, both by providing the same money amounts and by creating a temporal wedge between trust game tasks. Stage 2, 3 and 4 trust games were as in the other treatments, to mirror the information provided in stages 2, 3 and 4 of the other treatments, the computer screen displayed information on average giving rate and average return rate, with a summary table on average giving and return rates from stage 2 onwards being provided at the end of each stage. None of the HHZ treatments tried to control for risk aversion, loss aversion, ambiguity aversion and experimenter demand sensitivity by the means of end of experiment tasks.

\section{Experimental results}

\subsection{Giving and return rates ${ }^{21}$}

We define the giving rate as the fraction of the endowment given by trusters to trustees, and the return rate as the fraction of the amount received by trusters which is returned by the trustees to the trusters (where the amount received by trustees is 3 times what was given in all treatments).

Figure 1 displays giving and return rates in the key treatments $(84, S 8$ and $S 4)$ highlighting the role of majorities, minorities and one group framing. ${ }^{22}$ Table 2 displays giving and return rates across stages in all treatments, including the various controls. Table 3 employs regression analysis on mean Stage 2-4 giving and return rate by each subject to verify treatment effects and the role of possible covariates.

\footnotetext{
${ }^{20}$ A second small difference concerned the matching rule. HHZ's matching rule ensure that in every stage subjects were precisely matched the same number of times with insiders and outsiders, although this implied that the likelihood of being rematched with insiders and outsiders was slightly different. We could not retain this constraint with the uneven number of subjects in our key treatments and so we opted instead for pure random matching in our experiment, with any other subject in the room being equally likely to be matched with any given subject, no matter the group.

${ }^{21}$ Throughout the paper, in bivariate tests statistical significance is estimated by treating session averages as the unit of observation, in order to control for possible non-independence of choices within each session. Also throughout the paper, all reported tests are two tailed except where otherwise specified

${ }^{22}$ We verified whether there is any difference in giving and return rates between the three sessions where the Blue group was the majority group and the three sessions where the Red group was the majority group. While samples are too small to make meaningful comparison $(n=6)$, the only difference reaching significance is between average return rates (Mann-Whitney $P=0.05$ ) but this is only different by around $3-4 \%$ and it is so already from stage 1 .
} 
Fig. 1 Giving and return rates in Stages 2-4
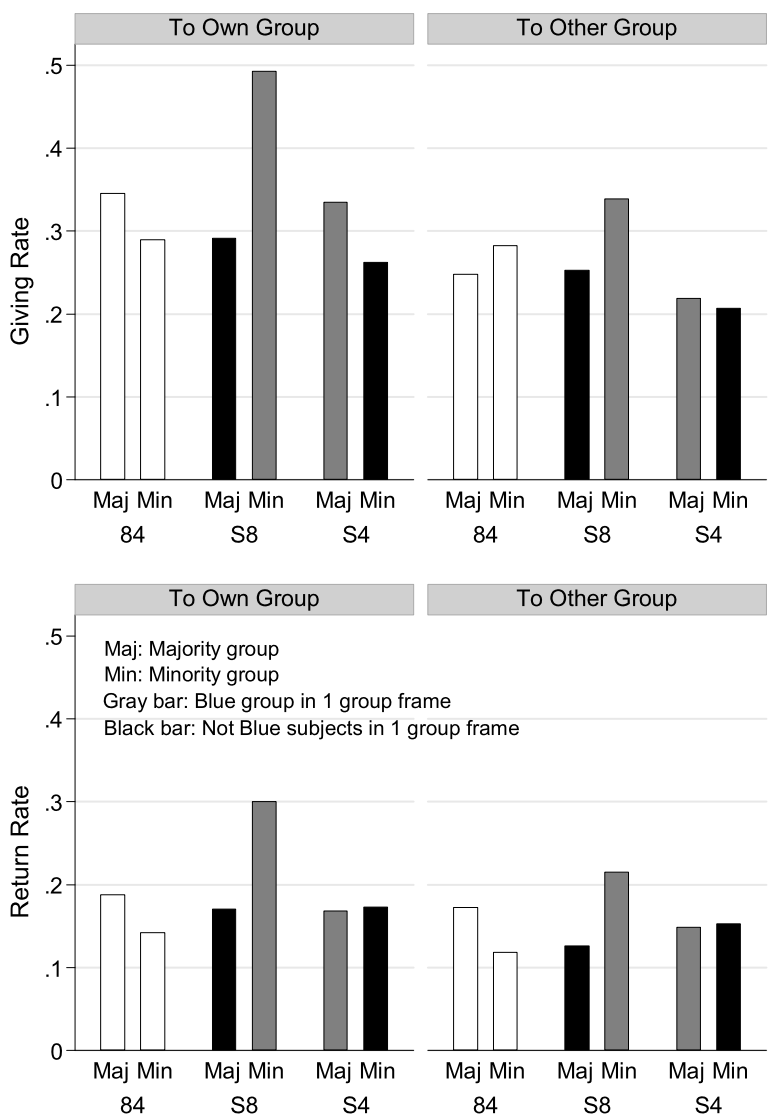

Table 2 Giving and return rates

\begin{tabular}{|c|c|c|c|c|c|c|c|}
\hline & $B$ & 66 & 88 & 44 & 84 & $S 8$ & $S 4$ \\
\hline Stage 1 giving rate & 0.562 & 0.457 & 0.433 & 0.350 & 0.367 & 0.477 & 0.413 \\
\hline Stage $2-4$ giving rate & 0.558 & 0.369 & 0.316 & 0.303 & 0.305 & 0.318 & 0.275 \\
\hline to own group members & & 0.449 & 0.348 & 0.344 & 0.333 & 0.334 & 0.319 \\
\hline to other group members & & 0.288 & 0.289 & 0.249 & 0.265 & 0.296 & 0.213 \\
\hline Stage 1 return rate & 0.318 & 0.219 & 0.270 & 0.304 & 0.226 & 0.270 & 0.238 \\
\hline Stage 2-4 return rate & 0.252 & 0.153 & 0.173 & 0.157 & 0.166 & 0.189 & 0.163 \\
\hline to own group members & & 0.200 & 0.185 & 0.187 & 0.177 & 0.204 & 0.170 \\
\hline to other group members & & 0.106 & 0.161 & 0.110 & 0.148 & 0.168 & 0.151 \\
\hline
\end{tabular}

Regressions 1 and 2 refer to giving rates when subjects play with own and other group members respectively. Regressions 3 and 4 are on return rates. In the regressions, error clustering is used to take into account the possible non-independence of 
Table 3 Regressions on mean giving and return rate

\begin{tabular}{|c|c|c|c|c|c|c|}
\hline \multirow{2}{*}{$\begin{array}{l}\text { Regressions on stage } \\
2-4 \text { mean giving rate }\end{array}$} & \multicolumn{3}{|c|}{ Regression 1 (to own group) } & \multicolumn{3}{|c|}{ Regression 2 (to other group) } \\
\hline & $\beta$ & $t$ & $p$ & $\beta$ & $t$ & $p$ \\
\hline Stage 1 giving rate & 0.424 & 7.93 & 0.000 & 0.293 & 5.51 & 0.000 \\
\hline Stage 1 return rate & 0.143 & 1.92 & 0.064 & 0.242 & 3.32 & 0.002 \\
\hline Group & -0.059 & -0.72 & 0.477 & -0.214 & -3.16 & 0.003 \\
\hline GroupOf8 & -0.061 & -0.63 & 0.536 & 0.012 & 0.20 & 0.841 \\
\hline GroupOf4 & -0.040 & -0.43 & 0.669 & -0.017 & -0.29 & 0.771 \\
\hline Majority & -0.010 & -0.13 & 0.899 & -0.045 & -1.15 & 0.258 \\
\hline Minority & 0.020 & 0.29 & 0.774 & 0.061 & 1.27 & 0.211 \\
\hline NotBlue & -0.117 & -2.17 & 0.037 & -0.048 & -0.98 & 0.335 \\
\hline Gender & -0.040 & -1.34 & 0.190 & -0.004 & -0.12 & 0.904 \\
\hline EcMgt & -0.012 & -0.40 & 0.695 & -0.021 & -0.89 & 0.380 \\
\hline UK & 0.062 & 2.00 & 0.053 & 0.039 & 1.77 & 0.086 \\
\hline China & 0.015 & 0.30 & 0.764 & -0.023 & -0.55 & 0.588 \\
\hline Age & 0.000 & -0.14 & 0.890 & 0.002 & 1.09 & 0.284 \\
\hline \multirow[t]{2}{*}{ Constant } & 0.272 & 3.32 & 0.002 & 0.246 & 3.29 & 0.002 \\
\hline & \multicolumn{3}{|c|}{$n=328, R^{2}=0.324$} & \multicolumn{3}{|c|}{$n=327, R^{2}=0.366$} \\
\hline \multirow{2}{*}{$\begin{array}{l}\text { Regressions on stage } \\
2-4 \text { mean return rate }\end{array}$} & \multicolumn{3}{|c|}{ Regression 3 (to own group) } & \multicolumn{3}{|c|}{ Regression 4 (to other group) } \\
\hline & $\beta$ & $t$ & $p$ & $\beta$ & $t$ & $p$ \\
\hline Trust rate as 2 nd mover & 0.131 & 2.38 & 0.023 & 0.089 & 1.56 & 0.128 \\
\hline Stage 1 giving rate & 0.060 & 1.82 & 0.078 & 0.015 & 0.51 & 0.615 \\
\hline Stage 1 return rate & 0.186 & 2.67 & 0.012 & 0.230 & 5.62 & 0.000 \\
\hline Group & -0.009 & -0.28 & 0.783 & -0.095 & -2.60 & 0.014 \\
\hline GroupOf8 & -0.003 & -0.12 & 0.906 & 0.036 & 1.51 & 0.141 \\
\hline GroupOf4 & -0.012 & -0.45 & 0.657 & -0.014 & -0.58 & 0.568 \\
\hline Majority & -0.006 & -0.30 & 0.765 & -0.005 & -0.20 & 0.845 \\
\hline Minority & 0.013 & 0.35 & 0.731 & 0.069 & 2.17 & 0.037 \\
\hline NotBlue & -0.026 & -1.35 & 0.186 & -0.031 & -1.32 & 0.197 \\
\hline Gender & -0.029 & -1.60 & 0.120 & -0.019 & -0.86 & 0.396 \\
\hline EcMgt & -0.031 & -1.63 & 0.112 & 0.014 & 0.53 & 0.599 \\
\hline UK & -0.012 & -0.62 & 0.542 & -0.019 & -1.02 & 0.316 \\
\hline China & -0.015 & -0.59 & 0.561 & -0.057 & -1.93 & 0.062 \\
\hline Age & 0.000 & 0.24 & 0.808 & 0.001 & 0.43 & 0.671 \\
\hline Constant & 0.100 & 1.79 & 0.083 & 0.126 & 1.95 & 0.059 \\
\hline & \multicolumn{3}{|c|}{$n=324, R^{2}=0.175$} & \multicolumn{3}{|c|}{$n=318, R^{2}=0.234$} \\
\hline
\end{tabular}

Notes: We employ error clustering to control for session level effects 
observations by different subjects in the same session. ${ }^{23}$ We have treatment dummies for Group (=1 in all treatments except $B$ ), GroupOf8 and GroupOf4 (=1 if subject belongs to group of 8 subjects or 4 subjects, respectively), Majority ( $=1$ if subject belongs to strict majority), Minority (= 1 if subject belongs to strict minority) and NotBlue (= 1 if subject is in the low status framed group). The return rate regressions have Giving Rate received as the Second Mover as an independent variable: that is, the mean stages 2-4 giving rate the subject has received when playing as a trustee. This allows us to control for the positive relationship which we might expect between giving rate and return rate. Both giving and return rate regressions control for Stage 1 giving and return rates. ${ }^{24}$ Various dummy variables capture individualspecific heterogeneity: stage 1 giving and return rate, age, and dummies for gender (= 1 for women), economics or management educational background (=1 if applicable) and nationality (UK $=1$ for UK subjects and China $=1$ for Chinese subjects).

Result 1 Low status subjects trust less other low status subjects.

Support Figure 1 is suggestive of this result as trust rates from low status subjects to other low status subjects appear lower than trust rates from high status subjects to other high status subjects in both $S 8$ and $S 4$. According to Regression 1, low status (Not Blue) subjects give 12 percentage points less to other low status subjects ( $P=$ $0.037)$. Figure 1 clearly shows, in relation to one frame treatment sessions, that Not Blue subjects give less to other Not Blue subjects. While Blue trusters gave $40.6 \%$ of their endowment to other Blue trusters, Not Blue trusters only gave $26.2 \%$ of their endowment (Wilcoxon $P=0.028$ ) in the 10 sessions of $S 8$ and $S 4$ treatments.

Result 2 Controlling for covariates, minority subjects return more to majority subjects.

Support Regression 4 in Table 3 shows that minority subjects have a higher return rate (by 7 percentage points) towards majority subjects, and this is statistically significant $(P=0.037)$. Among the key treatments, Fig. 1 shows that this result is not apparent from 84 and $S 4$ and appears to be driven by treatment $S 8$, where the minority subjects are also the low status group.

Other results Overall, there remains evidence for negative discrimination both in giving rates and in return rates. We could not find any statistically significant change in discrimination in either giving or return rates across rounds in different treatments. ${ }^{25}$ Regressions 1 and 3 in Table 3 show that the introduction of groups per

\footnotetext{
${ }^{23}$ We have also run random effects regressions getting the same broad picture in terms of mean giving rates, whereas estimates of regressions on mean return rates collapses to OLS estimates due to zero variance being explained by the session level random coefficients; this leaves OLS with error clustering as the better estimation option.

${ }^{24}$ This might occur for a number of psychological motives which have been documented in other experiments, such as inequality aversion (Fehr and Schmidt 1999), reciprocity (Falk and Fischbacher 2001) or trust responsiveness (Guerra and Zizzo 2004).

${ }^{25}$ Each round average level for each session was the unit of observation that was matched with period number for computing these correlations.
} 
se does not increase giving and return rates to same group members; the coefficients are actually negative, albeit statistically insignificant. Regressions 2 and 4 show that, when controlling for a number of covariates including (in relation to return rates) behavioral reciprocity, the introduction of groups decreases giving rates to the other group members by around 20 percentage points and return rates by around 9 percentage points. Clearly, when it comes to majority and high status subjects, there is no reason to expect anything other than negative discrimination. We also could not find any statistically significant change in discrimination in either giving or return rates across rounds in different treatments. ${ }^{26}$

In Table 3, discrimination in giving rate is defined (as in HHZ) as giving rate (stages 2-4) in group treatments minus giving rate (stages 2-4) in $B$ treatment (similarly for the return rate). An alternative measure would be to consider [giving rate (stages 2-4) - giving rate (stage 1) in group treatments] minus [giving rate (stages 2-4) - giving rate (stage 1) in $B$ treatment]. A parallel measure could be construed for the return rate. ${ }^{27} \mathrm{~A}$ difficulty with these measures is that they do not prevent the possibility that in stage 1 of the group treatments giving and return rates may already be affected by the expectation of interaction with non-group members, which may lead subjects prone to negative group discrimination to already lower their giving and return rate in stage 1 . The comparatively low giving rate and return rate already in stage 1 of the groups treatments, relative to the $B$ treatment, is at least consistent with this possibility. ${ }^{28}$ Nevertheless, even if these alternative measures are used, the finding on negative discrimination remains is replicated, at least in relation to giving rates (see online Appendix B).

Our regression analysis in Table 3 controls for absolute group size effects and finds no evidence for them as GroupOf8 and GroupOf4 are statistically insignificant in all regressions of Table 3 . A cursory look at Table 2 confirms this view, with giving and return rates in 44, 66 and 88 being similar and with no trend upwards or downwards based on group size.

Among the other covariates of Table 3, there is evidence of a relationship between giving and return rate in Regressions 1, 2 and 3, though less so in Regression 4 ( $P=0.064$, one tailed). There is also various (though not universal) evidence of dependence on giving and/or return rates in stage 1 , which may be due to a combination of individual characteristics and learning dynamics. ${ }^{29}$

\footnotetext{
${ }^{26}$ Each round's average level for each session was the unit of observation that was matched with round number for computing these correlations.

${ }^{27}$ A nice feature of these measures is that, like those of Table 3, they do control for learning effects. Conversely, a simpler measure of these measures that neglected the B treatment information entirely and simply focused on 'giving rate (stages 2-4) - giving rate (stage 1) in group treatments' cannot separate out the effect of group information from that of learning effects.

${ }^{28}$ Regressions on stage 1 giving and return rates are presented in the online Appendix B. They show that return rates are indeed statistically significantly lower already in stage 1 in the B treatment than in the group treatments; however, this is not significantly the case for giving rates.

${ }^{29}$ The two may of course interact: for example, subjects may acquire information about the social preference distribution in the population by the stage 1 play experience (e.g., Levine 1998). No individual specific dummy variable is statistically significant at $P<0.05$ or better, although there is marginal evidence $(P<0.1)$ for UK subjects to give more (Regressions 1 and 2$)$ and for Chinese students to return less to different group status subjects (Regression 4).
} 


\subsection{Perceived values and discrimination}

We now focus on the treatments with groups. This is (a) to try to get an understanding about whether subjects value groups equally depending on whether they are majority or minority groups, or whether they are framed as not belonging to any group at all; and (b) to get a better understanding of discrimination using perceived value information and, in the subset of experimental treatments that we ran (and so excluding 66 from $\mathrm{HHZ}$ ), information from the end of experiment tasks.

Perceived value measurement We measure perceived value subjects placed on own group membership by the extent to which subjects place a value on own group membership in excess of its material value. The markets at the start of stages 2, 3 and 4 provided an incentive-compatible mechanism for the revelation of individual preferences for staying in one's own group (the willingness to accept, WTA, value) or for switching groups (the willingness to pay, WTP, value). As there were repeated markets, subjects also had the opportunity to gain experience both about the nature of the social commodity being traded (i.e. membership of a given group) and about the market mechanism itself. ${ }^{30}$

WTA(own) is the positive price a subject needed to be paid to be willing to switch and WTP(own) is equivalent to a negative price on own group membership, and so they reveal the value that an individual places on membership of his or her group. Figure 2 provides information on WTA and WTP values observed in the experiment.

We use HHZ's simple perceived value measure $M$ as equal for each subject and market to WTA(own) or-WTP(own), whichever is the case. ${ }^{31}$ All of our experimental treatments, and 66 from HHZ, are such that group membership does not imply, either directly or in terms of frequency of interaction, a financial advantage in being inside rather than outside a group. It is possible, however, that, if subjects find that one group is more profitable than another in terms of actual history of trust and trustworthiness with respect to the two groups, this may affect group valuations. We address this endogeneity problem by including regression analysis with stage 2 psychological values as dependent variable, as stage 2 valuations are provided before any feedback is received on within-group andbetween-group performance. ${ }^{32}$

\footnotetext{
${ }^{30} \mathrm{HHZ}$ discuss whether this is a genuine psychological benefit rather than the artifact of well known mechanisms, like reference dependence. They conclude that, at least partially, it corresponds to genuine perceived value.

${ }^{31} \mathrm{In} \mathrm{HHZ}$, this is the most effective measure in predicting discrimination, but we shall refer to other measures in the next footnote.

${ }^{32}$ One could still argue, even in this case, that what matters is the expectation of material gains from belonging to a given group, and, while under the null hypothesis of no discrimination these should not differ between treatments, the same cannot be guaranteed if this null hypothesis is rejected. To address this point, we also carried robustness checks in our analysis by computing the following expectation-corrected measure (see online Appendices D and E): we take M minus the expectation of the material gain from a switch when these expectations of material gains are formed rationally (i.e., the expected relative material gain/loss is the same as actually occurs by remaining in the group in stage 2).
} 
Fig. 2 Histogram of willingness to pay $(W T P)$ and willingness to accept (WTA) in relation to the other group

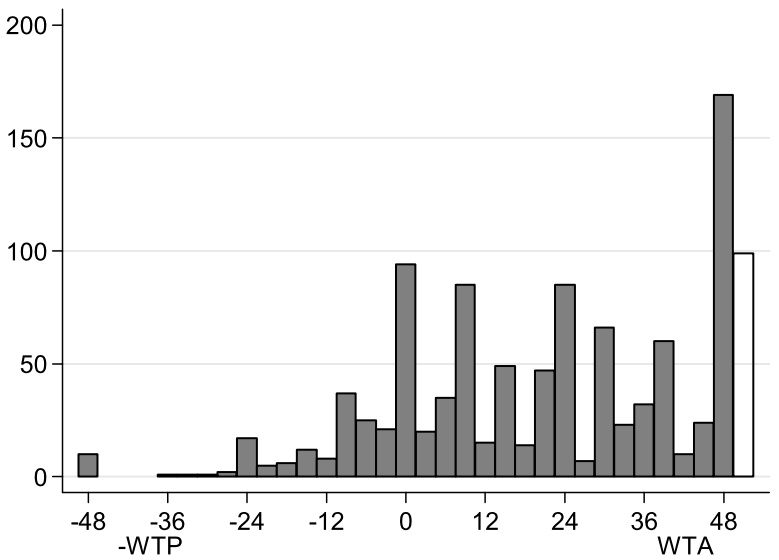

Notes: The histograms are built from individual choices; $n=210$ for - WTP observations $($ mean $=9.986$, standard deviation $($ s.d. $)=$ $11.759)$ and $n=810$ (mean $=30.095$, s.d. $=16.132)$ for WTA observations. The white column stands for choices of not being willing to accept any price up to 48 to switch group

Another problem with the average $M$ measure of the mean psychological benefit from own group membership is that subjects could state that they were not willing to lose their membership at any allowed price between 0 and 48 points. $9.5 \%$ of the choices were of this 'definite stay' kind (between 5.6 and $13.4 \%$ in different treatments). We chose two routes to deal with this problem. M contains all observations, but conservatively introduces a valuation of 49 for these definite stays: since the lower bound for valuations was-48 (the budget), if anything, for $x>49$, this introduces a downward bias. Mb simply omits 'definite stay' observations and also introduces a downward bias in average $M$ estimates. Either way, in the light of possible downward biases, our average $\mathrm{M}$ estimates should be interpreted as conservative estimates of the revealed perceived values of own group membership.

Results on perceived values Table 4 presents $\mathrm{M}$ and $\mathrm{Mb}$ mean values by treatment, while Fig. 3 illustrates mean $\mathrm{M}$ and $\mathrm{Mb}$ values graphically focusing on our key treatments $84, S 8$ and $S 4 .{ }^{33}$

Figure 3 makes clear that for all groups in $84, S 8$ and $S 4$, including those framed as outsiders, the perceived value is positive. ${ }^{34}$ To investigate the determinants of perceived values, we present some regression analysis on $\mathrm{M}$ (Regressions 5 and 7) and

\footnotetext{
${ }^{33}$ The same qualitative results emerge if expectations-corrected measures of psychological values are used instead (see online Appendix $\mathrm{C}$ for details).

${ }^{34}$ Psychological value in all the sessions and whatever the measure used (Wicoxon $P<0.001$ across the 30 sessions of all treatments, including the controls). Note that psychological values are very similar between the three 84 sessions in which the Blue group is the majority group (e.g., $\mathrm{M}=22.241$ ) and those in which the Red group is the majority group (e.g., $\mathrm{M}=23.546$ ).
} 
Table 4 Mean psychological values

\begin{tabular}{|c|c|c|c|c|c|c|c|}
\hline \multirow[t]{2}{*}{ Treatment } & \multirow{2}{*}{ Stage } & \multicolumn{3}{|l|}{ M } & \multicolumn{3}{|l|}{$\mathrm{Mb}$} \\
\hline & & & Majority & Minority & & Majority & Minority \\
\hline \multirow[t]{4}{*}{66} & 2 & 21.04 & & & 19.83 & & \\
\hline & 3 & 24.65 & & & 23.02 & & \\
\hline & 4 & 21.06 & & & 17.81 & & \\
\hline & Total & 22.25 & & & 20.25 & & \\
\hline \multirow[t]{4}{*}{88} & 2 & 21.11 & & & 20.03 & & \\
\hline & 3 & 17.91 & & & 15.84 & & \\
\hline & 4 & 20.09 & & & 16.88 & & \\
\hline & Total & 19.70 & & & 17.61 & & \\
\hline \multirow[t]{4}{*}{44} & 2 & 24.95 & & & 24.33 & & \\
\hline & 3 & 24.40 & & & 22.41 & & \\
\hline & 4 & 22.45 & & & 19.50 & & \\
\hline & Total & 23.93 & & & 22.14 & & \\
\hline \multirow[t]{5}{*}{84} & 2 & 21.94 & 24.31 & 17.21 & 21.56 & 24.31 & 15.83 \\
\hline & 3 & 24.71 & 27.63 & 18.88 & 21.67 & 24.57 & 16.14 \\
\hline & 4 & 22.03 & 24.15 & 17.79 & 17.16 & 18.41 & 14.95 \\
\hline & Total & 22.89 & 25.36 & 17.96 & 20.23 & 22.61 & 15.64 \\
\hline & & & (NotBlue) & (Blue) & & (NotBlue) & \\
\hline \multirow[t]{5}{*}{ S8 } & 2 & 18.72 & 11.40 & 33.35 & 15.96 & 10.44 & 29.44 \\
\hline & 3 & 20.90 & 18.63 & 25.45 & 15.94 & 15.25 & 17.60 \\
\hline & 4 & 16.08 & 10.95 & 26.35 & 11.02 & 6.72 & 20.69 \\
\hline & Total & 18.57 & 13.66 & 28.38 & 14.33 & 10.79 & 22.68 \\
\hline & & & (Blue) & (NotBlue) & & (Blue) & (NotBlue) \\
\hline \multirow[t]{4}{*}{$S 4$} & 2 & 31.23 & 34.70 & 24.30 & 28.89 & 33.11 & 19.94 \\
\hline & 3 & 26.73 & 32.40 & 15.40 & 22.80 & 28.88 & 11.67 \\
\hline & 4 & 25.27 & 30.18 & 15.45 & 22.13 & 28.65 & 7.06 \\
\hline & Total & 27.74 & 32.43 & 18.38 & 24.63 & 30.24 & 12.98 \\
\hline
\end{tabular}

$\mathrm{Mb}$ (Regressions 6 and 8) in Table 5, again controlling for possible session level specific effects by using error clustering; Table 6 has the corresponding regressions with just stage $2 \mathrm{M}$ (Regressions 9 and 11) and Mb (Regressions 10 and 12) as dependent variables. $^{35}$

\footnotetext{
${ }^{35}$ Random effects regressions on perceived values collapse to OLS estimates due to zero variance being explained by the session level random coefficients; this again leaves OLS with error clustering as the better estimation option.
} 
Fig. 3 Mean psychological values
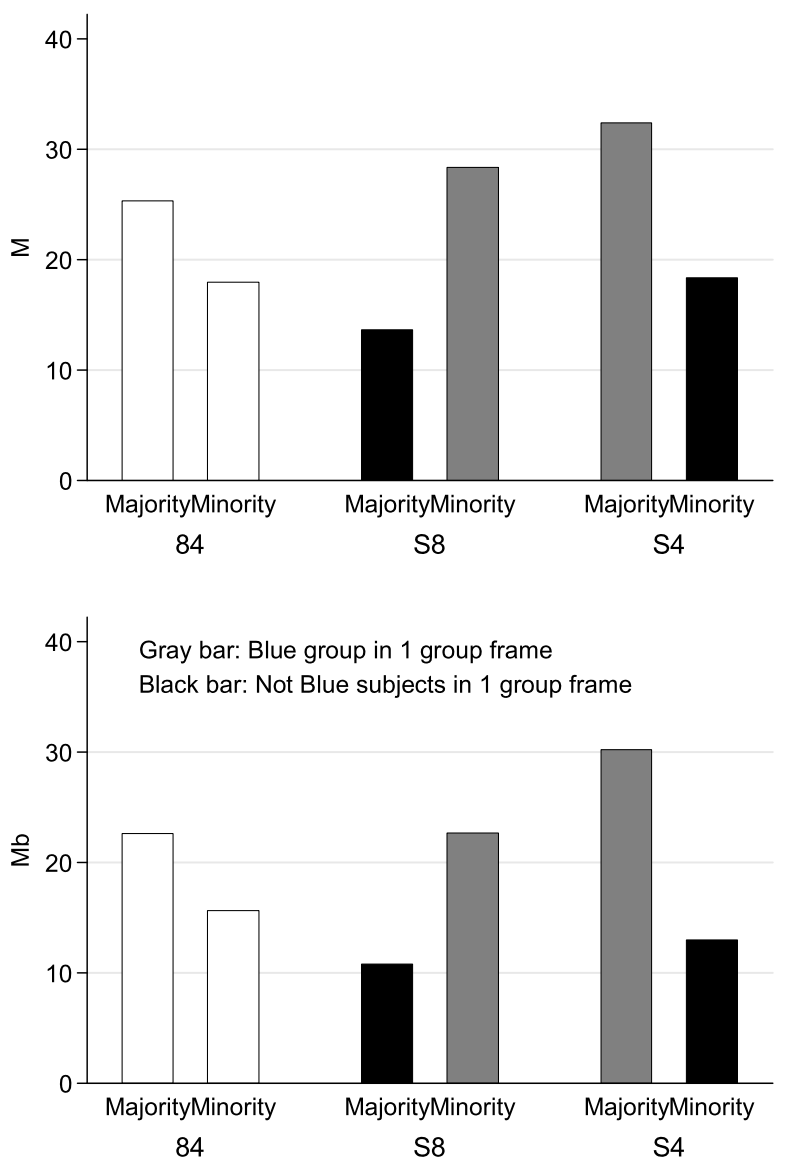

The independent variables are all those from Table 3 that can be defined in the subsample. Regressions 7 and 8 restrict the samples to those sessions for which end of experiment tasks have been measured, thus both treatments $B$ and 66 are excluded. While losing statistical power, these analyses are able to include Holt and Laury (2002) variants proxies for Risk Aversion, Loss Aversion, Ambiguity Aversion and EDE Sensitivity, i.e. sensitivity to experimenter demand effects. Risk aversion is proxied by the number of risk averse choices in the domain of gains; Loss Aversion by the sum of risk averse choices in the domain of gains and risk loving choices in the domain of losses; Ambiguity Aversion and EDE Sensitivity respectively by the number of ambiguity averse and experimenter demand compliant choices.

Result 3 When covariates are controlled for, subjects appear to like being in majorities. In the differential status treatments, subjects dislike being in the low status group. 
Table 5 Regressions on psychological value

\begin{tabular}{|c|c|c|c|c|c|c|}
\hline & \multicolumn{3}{|c|}{ Regression 5, mean M } & \multicolumn{3}{|c|}{ Regression 6, mean $\mathrm{Mb}$} \\
\hline & $\beta$ & $t$ & $p$ & $\beta$ & $t$ & $p$ \\
\hline GroupOf8 & -2.233 & -1.15 & 0.258 & -3.152 & -1.29 & 0.207 \\
\hline Majority & 7.781 & 4.11 & 0.000 & 8.808 & 3.50 & 0.002 \\
\hline Minority & 2.817 & 0.77 & 0.447 & -0.237 & -0.06 & 0.954 \\
\hline NotBlue & -13.884 & -4.41 & 0.000 & -16.308 & -4.51 & 0.000 \\
\hline Gender & 3.223 & 1.71 & 0.098 & 3.138 & 1.58 & 0.125 \\
\hline EcMgt & -3.988 & -1.62 & 0.115 & -3.410 & -1.27 & 0.215 \\
\hline UK & 1.249 & 0.63 & 0.535 & 2.260 & 1.16 & 0.254 \\
\hline China & -3.925 & -1.41 & 0.168 & -5.011 & -1.52 & 0.138 \\
\hline Age & 0.323 & 1.82 & 0.079 & 0.161 & 0.86 & 0.395 \\
\hline \multirow[t]{4}{*}{ Constant } & 13.842 & 2.42 & 0.022 & 15.828 & 2.85 & 0.008 \\
\hline & \multicolumn{3}{|c|}{$n=358, R^{2}=0.113$} & \multicolumn{3}{|c|}{$n=353, R^{2}=0.126$} \\
\hline & \multicolumn{3}{|c|}{ Regression 7, mean $\mathrm{M}$} & \multicolumn{3}{|c|}{ Regression 8, mean $\mathrm{Mb}$} \\
\hline & $\beta$ & $t$ & $p$ & $\beta$ & $t$ & $p$ \\
\hline GroupOf8 & -3.291 & -1.63 & 0.116 & -4.392 & -2.18 & 0.039 \\
\hline Majority & 7.499 & 3.52 & 0.002 & 8.856 & 3.24 & 0.004 \\
\hline Minority & 1.680 & 0.50 & 0.624 & -1.264 & -0.34 & 0.733 \\
\hline NotBlue & -13.487 & -4.56 & 0.000 & -15.970 & -4.47 & 0.000 \\
\hline Gender & 3.846 & 1.76 & 0.091 & 3.969 & 1.79 & 0.087 \\
\hline EcMgt & -4.318 & -1.57 & 0.128 & -4.102 & -1.38 & 0.180 \\
\hline UK & 1.383 & 0.57 & 0.575 & 2.010 & 0.79 & 0.438 \\
\hline China & -5.939 & -2.31 & 0.030 & -7.258 & -2.14 & 0.043 \\
\hline Age & 0.233 & 0.97 & 0.342 & 0.106 & 0.43 & 0.669 \\
\hline Risk Aversion & -1.368 & -0.71 & 0.485 & -0.484 & -0.26 & 0.793 \\
\hline Loss Aversion & 1.381 & 0.62 & 0.543 & 0.464 & 0.22 & 0.829 \\
\hline $\begin{array}{l}\text { Ambiguity } \\
\text { Aversion }\end{array}$ & -2.110 & -0.90 & 0.376 & -0.805 & -0.36 & 0.719 \\
\hline EDE Sensitivity & 0.170 & 0.34 & 0.740 & 0.094 & 0.16 & 0.873 \\
\hline Constant & 21.490 & 2.73 & 0.012 & 20.405 & 2.83 & 0.009 \\
\hline & \multicolumn{3}{|c|}{$n=294, R^{2}=0.159$} & \multicolumn{3}{|c|}{$n=289, R^{2}=0.159$} \\
\hline
\end{tabular}

Notes: We employ error clustering to control for session level effects

Support We are not able to detect statistically significant differences between aggregate majority and minority mean values. However, in the regression analysis where covariates are controlled for, we find that the Majority dummy is significant across all regressions: subjects are willing to pay 5-9 points more on average for being in a majority group $(P<0.05)$. 
Table 6 Regressions on Stage 2 psychological value

\begin{tabular}{|c|c|c|c|c|c|c|}
\hline & \multicolumn{3}{|c|}{ Regression 9, mean $\mathbf{M}$} & \multicolumn{3}{|c|}{ Regression 10 , mean $\mathrm{Mb}$} \\
\hline & $\beta$ & $t$ & $p$ & $\beta$ & $t$ & $p$ \\
\hline GroupOf8 & -0.496 & -0.20 & 0.845 & -0.936 & -0.37 & 0.715 \\
\hline Majority & 5.050 & 2.25 & 0.032 & 6.100 & 3.16 & 0.004 \\
\hline Minority & 7.219 & 1.69 & 0.101 & 3.821 & 0.77 & 0.447 \\
\hline NotBlue & -13.573 & -4.31 & 0.000 & -15.311 & -5.21 & 0.000 \\
\hline Gender & 3.252 & 1.40 & 0.171 & 3.109 & 1.37 & 0.181 \\
\hline EcMgt & -3.033 & -0.95 & 0.352 & -2.342 & -0.72 & 0.474 \\
\hline UK & 4.665 & 2.15 & 0.040 & 5.477 & 2.52 & 0.017 \\
\hline China & 0.393 & 0.10 & 0.923 & 0.659 & 0.17 & 0.864 \\
\hline Age & 0.516 & 2.60 & 0.015 & 0.448 & 2.25 & 0.032 \\
\hline Constant & 6.825 & 1.21 & 0.237 & 7.397 & 1.26 & 0.218 \\
\hline & $n=358, R^{2}=0.0$ & 070 & & $n=340, R^{2}=$ & 076 & \\
\hline & Regression & on 11 , mean $\mathrm{M}$ & & Regressiol & , mean $\mathrm{M}$ & \\
\hline & $\beta$ & $t$ & $p$ & $\beta$ & $t$ & $p$ \\
\hline GroupOf8 & -3.496 & -1.66 & 0.110 & -5.054 & -2.66 & 0.014 \\
\hline Majority & 4.945 & 2.09 & 0.047 & 6.442 & 3.37 & 0.003 \\
\hline Minority & 4.609 & 1.09 & 0.286 & 0.571 & 0.12 & 0.908 \\
\hline NotBlue & -13.658 & -4.41 & 0.000 & -15.345 & -5.07 & 0.000 \\
\hline Gender & 4.018 & 1.63 & 0.116 & 3.5 & 1.45 & 0.160 \\
\hline EcMgt & -6.161 & -1.62 & 0.119 & -5.141 & -1.38 & 0.179 \\
\hline $\mathrm{UK}$ & 4.049 & 1.43 & 0.165 & 5.129 & 1.73 & 0.096 \\
\hline China & 2.562 & 0.56 & 0.578 & 2.909 & 0.68 & 0.502 \\
\hline Age & 0.451 & 1.85 & 0.077 & 0.362 & 1.48 & 0.153 \\
\hline Risk Aversion & -1.224 & -0.51 & 0.616 & -0.818 & -0.33 & 0.743 \\
\hline Loss Aversion & 1.852 & 0.73 & 0.470 & 1.415 & 0.55 & 0.589 \\
\hline Ambiguity Aversion & 2.372 & 0.91 & 0.371 & 1.775 & 0.66 & 0.515 \\
\hline EDE Sensitivity & 0.082 & 0.13 & 0.899 & 0.131 & 0.19 & 0.851 \\
\hline Constant & 12.742 & 1.62 & 0.118 & 13.461 & 1.66 & 0.110 \\
\hline & $n=294, I$ & $R^{2}=0.100$ & & $n=278$, & $=0.102$ & \\
\hline
\end{tabular}

Notes: We employ error clustering to control for session level effects

In relation to the second part of the result, consistently across Tables 5 and 6 regressions, the coefficients on NotBlue willing imply that subjects are willing to pay less for being low status members by $13-16$ points $(P<0.001)$. This is further corroborated by bivariate tests (Wicoxon $P<0.007$ in relation to the $\mathrm{M}$ measure and $P<0.037$ in relation to the $\mathrm{Mb}$ measure in the 10 sessions of $S 4$ and $S 8$ ): in 
treatment $S 8$, Blue's mean perceived value is 28 points, whereas Not Blue's mean perceived value is just 13 points, i.e. just around half as much. ${ }^{36}$ In $S 4$, the perceived values of Blue and Not Blue are 32 and 18 respectively. ${ }^{37}$

Explaining discrimination Let DGivingRate (DReturnRate) be equal to mean giving (return) rate by a subject to same group status subjects minus mean giving (return) rate by the same subject to different group status subjects. To investigate discrimination further, we ran regressions, controlling for session specific effects using error clustering, on DGivingRate (Regressions 13-18) and DReturnRate (Regressions 1924). ${ }^{38}$ Tables 7 and 8 give the results of these regressions.

Regression 13 contains the same independent variables as the regressions in Table 5. Regression 14 adds stage $2 \mathrm{M}$ and Regression 15 adds interaction terms between stage $2 \mathrm{M}$ and GroupOf8, Majority, Minority and NotBlue. Regressions 16-18 are the corresponding regressions adding the end of experiment task variables (and working on the subset of sessions for which the end of experiment task data is available). Regressions 19-24 are the corresponding regressions to Regressions 13-18 but with DReturnRate as the dependent variable and DGiving Rate as Second Mover as an added independent variable (defined as the giving rate from insiders minus the giving rate from outsiders which the subject has experienced as a trustee). ${ }^{39}$

Result 4 Subjects who value their group more give comparatively more to insiders than to outsiders. Low status subjects discriminate less in giving rates between insiders and outsiders, and, when covariates are controlled for, minority subjects discriminate less in return rates against majority subjects.

Support The $\mathrm{M}$ dummy is positive and significant in all regressions which include it $(P<0.02)$. Regressions $13-16$ show that Not Blue subjects discriminate less by about $8 \%$. This fits with Result 1 that being labeled as an outsider to the one group depresses giving rates to other outsiders. We also just determined that NotBlue is a negative predictor of perceived value (Result 3 and Tables 5 and 6). That being the case, it is not surprising that NotBlue becomes statistically insignificant as perceived value measures are introduced: its effect appears to operate through the impact it has on perceived value, which, in turn and as in HHZ, predicts less discrimination in

\footnotetext{
${ }^{36}$ The contrast remains if $\mathrm{M}(\mathrm{RE})$ and $\mathrm{M}(\mathrm{AE})$, psychological values with rational and adaptive expectations respectively, are used, and so does not appear to be explained by different group membership profitability expectations. Table 4 also shows that the gap in perceived value persists throughout the experiment. One implication of high perceived values is social inertia, in the sense that subjects tend to stay in their group rather than switch: only $11.6 \%$ of choices result in a group switching deal (between $8.9 \%$ and $14.8 \%$ depending on the treatment).

${ }^{37}$ As shown in regressions in online Appendix D, both parts of the result are robust to having mean expectations-dependent $\mathrm{M}$ values (i.e., dependent on expectations of material gains) across the experiment as dependent variable; the second part is however more robust than the first part, as it is replicated also when expectations-dependent $M$ values from stage 2 only are used as dependent variable.

${ }^{38}$ Random effects regressions are presented in online Appendices $\mathrm{E}$ and $\mathrm{F}$.

${ }^{39}$ Online Appendices $\mathrm{E}$ and $\mathrm{F}$ consider a number of other regression specifications respectively for DGivingRate and DReturnRate, including the use of $\mathrm{Mb}$, expectations-dependent $\mathrm{M}$, and $\mathrm{M}$ variables based on average evaluations across all stages rather than just stage 2 .
} 
Table 7 Regressions on DGivingRate

\begin{tabular}{|c|c|c|c|c|c|c|c|c|c|}
\hline & \multicolumn{3}{|c|}{ Regression 13} & \multicolumn{3}{|c|}{ Regression 14} & \multicolumn{3}{|c|}{ Regression 15} \\
\hline & $\beta$ & $t$ & $p$ & $\beta$ & $t$ & $p$ & $\beta$ & $t$ & $p$ \\
\hline GroupOf8 & -0.066 & -1.22 & 0.231 & -0.065 & -1.21 & 0.236 & -0.042 & -0.38 & -0.198 \\
\hline Majority & 0.053 & 1.03 & 0.311 & 0.045 & 0.87 & 0.392 & 0.053 & -0.31 & 0.207 \\
\hline Minority & -0.038 & -0.96 & 0.347 & -0.051 & -1.27 & 0.213 & -0.008 & -0.88 & -0.556 \\
\hline NotBlue & -0.077 & -2.56 & 0.016 & -0.055 & -1.66 & 0.107 & -0.046 & 0.54 & 0.362 \\
\hline M & & & & 0.002 & 3.13 & 0.004 & 0.003 & -1.83 & 0.017 \\
\hline $\mathrm{M} \times$ GroupOf8 & & & & & & & -0.001 & 1.29 & 0.220 \\
\hline $\mathrm{M} \times$ Majority & & & & & & & 0.000 & 0.13 & 0.100 \\
\hline $\mathrm{M} \times$ Minority & & & & & & & -0.002 & 1.64 & 0.546 \\
\hline $\mathrm{M} \times$ NotBlue & & & & & & & -0.001 & -0.21 & -0.132 \\
\hline Gender & -0.040 & -1.37 & 0.182 & -0.046 & -1.57 & 0.127 & -0.046 & -0.06 & -0.014 \\
\hline EcMgt & 0.028 & 0.93 & 0.361 & 0.033 & 1.14 & 0.265 & 0.029 & 0.32 & -0.129 \\
\hline UK & 0.028 & 0.87 & 0.392 & 0.020 & 0.65 & 0.523 & 0.021 & 0.26 & -0.146 \\
\hline China & 0.035 & 0.91 & 0.368 & 0.035 & 0.91 & 0.370 & 0.038 & 0.10 & -0.046 \\
\hline Age & -0.002 & -1.17 & 0.253 & -0.003 & -1.59 & 0.123 & -0.003 & 0.12 & 0.033 \\
\hline \multirow[t]{4}{*}{ instant } & 0.192 & 2.56 & 0.016 & 0.180 & 2.47 & 0.019 & 0.152 & -0.17 & 0.014 \\
\hline & \multicolumn{3}{|c|}{$n=358, R^{2}=0.037$} & \multicolumn{3}{|c|}{$n=358, R^{2}=0.060$} & \multicolumn{3}{|c|}{$n=358, R^{2}=0.065$} \\
\hline & \multicolumn{3}{|c|}{ Regression 16} & \multicolumn{3}{|c|}{ Regression 17} & \multicolumn{3}{|c|}{ Regression 18} \\
\hline & $\beta$ & $t$ & $p$ & $\beta$ & $t$ & $p$ & $\beta$ & $t$ & $p$ \\
\hline GroupOf8 & -0.028 & -0.47 & 0.645 & -0.023 & -0.37 & 0.712 & -0.009 & -0.11 & 0.910 \\
\hline Majority & 0.044 & 0.76 & 0.454 & 0.037 & 0.63 & 0. & 0.064 & 0.84 & 0.410 \\
\hline Minority & -0.005 & -0.11 & 0.912 & -0.012 & -0.29 & 0.777 & 0.035 & 0.66 & 0.516 \\
\hline NotBlue & -0.079 & -2.41 & 0.024 & -0.058 & -1.63 & 0.117 & -0.049 & -0.81 & 0.424 \\
\hline M & & & & 0.002 & 2.64 & 0.014 & 0.003 & 2.54 & 0.018 \\
\hline $\mathrm{M} \times$ GroupOf8 & & & & & & & 0.000 & -0.21 & 0.836 \\
\hline $\mathrm{M} \times$ Majority & & & & & & & -0.001 & -0.90 & 0.377 \\
\hline $\mathrm{M} \times \mathrm{Min}$ & & & & & & & -0.002 & -1.09 & 0.284 \\
\hline $\mathrm{M} \times$ NotBlue & & & & & & & -0.001 & -0.53 & 0.599 \\
\hline Gender & -0.033 & -0.94 & 0.356 & -0.039 & -1.12 & 0.275 & -0.040 & -1.10 & 0.281 \\
\hline EcMgt & 0.004 & 0.12 & 0.904 & 0.013 & 0.43 & 0.669 & 0.014 & 0.46 & 0.647 \\
\hline UK & 0.025 & 0.67 & 0.509 & 0.019 & 0.52 & 0.611 & 0.024 & 0.65 & 0.524 \\
\hline China & 0.041 & 0.92 & 0.366 & 0.037 & 0.87 & 0.391 & 0.040 & 0.93 & 0.360 \\
\hline Age & -0.002 & -0.63 & 0.532 & -0.003 & -0.88 & 0.385 & -0.002 & -0.73 & 0.473 \\
\hline Risk Aversion & -0.001 & -0.04 & 0.970 & 0.001 & 0.01 & 0.988 & 0.002 & 0.06 & 0.952 \\
\hline Loss Aversion & 0.005 & 0.11 & 0.910 & 0.002 & 0.04 & 0.965 & 0.000 & -0.01 & 0.992 \\
\hline $\begin{array}{l}\text { Ambiguity } \\
\text { Aversion }\end{array}$ & 0.007 & 0.16 & 0.875 & 0.003 & 0.07 & 0.944 & 0.001 & 0.02 & 0.987 \\
\hline EDE Sensitivity & -0.003 & -0.77 & 0.450 & -0.003 & -0.77 & 0.449 & -0.003 & -0.73 & 0.471 \\
\hline Constant & 0.155 & 1.56 & 0.131 & 0.135 & 1.41 & 0.170 & 0.086 & 0.91 & 0.370 \\
\hline & $n=294$ & $=0.0$ & & $n=294$, & ${ }^{2}=0.0$ & & $n=29$ & $2=0$ & \\
\hline
\end{tabular}

Notes: DGivingRate is equal to the mean giving rate by a subject to same group status subjects minus mean giving rate by the same subject to different group status subjects. We employ error clustering to control for session level effects 
Table 8 Regressions on DReturnRate

\begin{tabular}{|c|c|c|c|c|c|c|c|c|c|}
\hline \multirow{3}{*}{$\begin{array}{l} \\
\text { DGiving rate as } \\
\text { 2nd mover }\end{array}$} & \multicolumn{3}{|c|}{ Regression 19} & \multicolumn{3}{|c|}{ Regression 20} & \multicolumn{3}{|c|}{ Regression 21} \\
\hline & $\beta$ & $t$ & $p$ & $\beta$ & $t$ & $p$ & $\beta$ & $t$ & $p$ \\
\hline & 0.085 & 1.89 & 0.068 & 0.086 & 1.91 & 0.066 & 0.091 & 1.99 & 0.056 \\
\hline GroupOf8 & -0.030 & -0.82 & 0.418 & -0.031 & -0.85 & 0.401 & -0.057 & -0.80 & 0.432 \\
\hline Majority & -0.031 & -0.84 & 0.405 & -0.024 & -0.66 & 0.511 & -0.074 & -0.96 & 0.345 \\
\hline Minority & -0.046 & -1.21 & 0.238 & -0.038 & -1.04 & 0.305 & -0.119 & -2.24 & 0.033 \\
\hline NotBlue & -0.006 & -0.13 & 0.897 & -0.022 & -0.50 & 0.620 & 0.064 & 0.82 & 0.417 \\
\hline M & & & & -0.001 & -1.81 & 0.080 & -0.002 & -2.18 & 0.037 \\
\hline $\mathrm{M} \times$ GroupOf8 & & & & & & & 0.001 & 0.60 & 0.556 \\
\hline$M \times N$ & & & & & & & 0.002 & 0.74 & 0.466 \\
\hline inority & & & & & & & 0.004 & 2.20 & 0.036 \\
\hline $\mathrm{M} \times$ NotBlue & & & & & & & -0.004 & -1.64 & 0.111 \\
\hline Gender & 0.004 & 0.12 & 0.904 & 0.007 & 0.25 & 0.807 & 0.015 & 0.54 & 0.595 \\
\hline EcMgt & -0.010 & -0.26 & 0.794 & -0.014 & -0.35 & 0.731 & -0.016 & -0.41 & 0.687 \\
\hline UK & 0.064 & 2.75 & 0.010 & 0.070 & 2.91 & 0.007 & 0.070 & 2.84 & 0.008 \\
\hline China & 0.046 & 1.09 & 0.283 & 0.047 & 1.10 & 0.280 & 0.044 & 1.03 & 0.309 \\
\hline Age & 0.002 & 0.99 & 0.329 & 0.003 & 1.33 & 0.195 & 0.003 & 1.32 & 0.199 \\
\hline \multirow[t]{4}{*}{ Constant } & 0.061 & 0.83 & 0.416 & 0.068 & 0.90 & 0.375 & 0.090 & 1.00 & 0.323 \\
\hline & \multicolumn{3}{|c|}{$n=355, R^{2}=0.034$} & \multicolumn{3}{|c|}{$n=355, R^{2}=0.045$} & \multicolumn{3}{|c|}{$n=355, R^{2}=0.063$} \\
\hline & \multicolumn{3}{|c|}{ Regression 22} & \multicolumn{3}{|c|}{ Regression 23} & \multicolumn{3}{|c|}{ Regression 24} \\
\hline & $\beta$ & $t$ & $p$ & $\beta$ & $t$ & $p$ & $\beta$ & $t$ & $p$ \\
\hline $\begin{array}{l}\text { DGiving rate as } \\
\text { 2nd mover }\end{array}$ & 0.069 & 1.34 & 0.193 & 0.070 & 1.37 & 0. & & 1.55 & 0.135 \\
\hline GroupOf8 & -0.004 & -0.09 & 0.930 & -0.010 & -0.20 & 0.845 & -0 & -0.74 & 0.468 \\
\hline Majority & -0.034 & -0.86 & 0.399 & -0.027 & -0.66 & 0.515 & 110 & -1.25 & 0.222 \\
\hline Minority & -0.023 & -0.45 & 0.655 & -0.016 & -0.33 & 0.743 & -0.160 & -2.48 & 0.021 \\
\hline NotBlue & -0.012 & -0.25 & 0.805 & -0.031 & -0.68 & 0.502 & 0.061 & 0.76 & 0.456 \\
\hline M & & & & -0.001 & -1.81 & 0.083 & -0.004 & -5.38 & 0.000 \\
\hline $\mathrm{M} \times \mathrm{C}$ & & & & & & & 0.002 & 0.88 & 0.388 \\
\hline $\mathrm{M} \times$ Majority & & & & & & & 0.003 & 1.23 & 0.229 \\
\hline $\mathrm{M} \times$ Minority & & & & & & & 0.006 & 4.21 & 0.000 \\
\hline $\mathrm{M} \times$ NotBlue & & & & & & & -0.004 & -1.57 & 0.129 \\
\hline Gender & -0.020 & -0.56 & 0.579 & -0.015 & -0.42 & 0.677 & -0.002 & -0.07 & 0.947 \\
\hline EcMgt & -0.029 & -0.66 & 0.517 & -0.038 & -0.85 & 0.406 & -0.045 & -1.04 & 0.307 \\
\hline UK & 0.041 & 1.47 & 0.154 & 0.047 & 1.64 & 0.114 & 0.038 & 1.27 & 0.216 \\
\hline China & 0.085 & 1.84 & 0.078 & 0.089 & 1.87 & 0.074 & 0.084 & 1.80 & 0.084 \\
\hline Age & 0.001 & 0.34 & 0.734 & 0.001 & 0.66 & 0.518 & 0.001 & 0.36 & 0.725 \\
\hline Risk Aversion & -0.056 & -2.11 & 0.046 & -0.057 & -2.14 & 0.042 & -0.055 & -1.85 & 0.076 \\
\hline Loss Aversion & 0.059 & 2.05 & 0.052 & 0.061 & 2.08 & 0.048 & 0.060 & 1.84 & 0.078 \\
\hline Ambiguity Aversior & n $\quad-0.054$ & -1.82 & 0.081 & -0.057 & -1.88 & 0.072 & -0.057 & -1.70 & 0.103 \\
\hline EDE Sensitivity & -0.004 & -0.65 & 0.523 & -0.004 & -0.62 & 0.540 & -0.004 & -0.72 & 0.480 \\
\hline Constant & 0.083 & 0.91 & 0.370 & 0.100 & 1.11 & 0.278 & 0.195 & 1.88 & 0.073 \\
\hline & $n=292$, & $R^{2}=0.0$ & 039 & $n=292$, & $R^{2}=0.0$ & & $n=292$, & $R^{2}=0$ & \\
\hline
\end{tabular}

Notes: DReturnRate is equal to the mean return rate by a subject to same group status subjects minus mean return rate by the same subject to different group status subjects. We employ error clustering to control for session level effects 
giving. The natural interpretation of this is that, because low status subjects dislike being low status, they discriminate less in giving.

Regarding the last part of the result on minorities, it fits with Result 2 on minorities returning more to majority subjects. When controlling for the $\mathrm{M}$ interaction terms, there is evidence that minority subjects discriminate less $(P<0.05$ in Regressions 21 and 24). ${ }^{40}$

Result 5 Subjects who value their group more return comparatively less to insiders relatively to outsiders. Minority subjects who value their group more discriminate more between insiders and outsiders.

Support Subjects who place more value on their own group discriminate less in reciprocating trust rather than more $(P<0.1,0.05,0.01,0.01$ in Regressions 19,20 , 23 and 24 respectively). Conversely, subjects placing more value in their minority groups discriminate more $\left(P<0.05\right.$ in Regressions 21 and 24). ${ }^{41}$

Other results In all regressions in Tables 5 through 8, our measure of EDE Sensitivity is uncorrelated with behavior. ${ }^{42}$ To the extent that they are proxied by our measure of EDE Sensitivity, experimenter demand effects do not explain perceived value or discrimination in either giving or return rates.

There is some evidence from Regressions 22-24 that risk averse subjects appear to discriminate less $(P<0.05$ or 0.06$)$, loss averse subjects may discriminate more $(P<0.05$ or 0.06$)$ and ambiguity averse subjects may also discriminate more $(P<$ 0.05 or 0.1$)$;

\section{Discussion}

As suggested by social identity theory as applied to the understanding of intergroup discrimination (e.g., Tajfel and Turner 2001), we find evidence of deference, in different ways, from low status and from minority subjects. In the psychological research, majorities and minorities can both display ingroup bias (Leonardelli and Brewer 2001), but our minority subjects discriminate less in return rates against majority subjects when covariates are controlled for (Result 4); and this appears to be connected to greater giving to majority members (Result 2). Our low status subjects are deferential with respect to the amount of trust they put in high status subjects, in the

\footnotetext{
${ }^{40}$ The first part of Result 4 is robust to all the alternative specifications considered in online Appendix E. The second part (on low group status subjects) is robust with expectations-dependent $\mathrm{M}$ unless interaction terms with M and Holt and Laury (2002) variants variables are simultaneously included, and is robust to all other specifications. The third part (on minority subjects) is robust across the different regression specifications in online Appendix F.

${ }^{41}$ The first part of the result is robust across the different regression specifications in online Appendix F. The second part is also robust, with the single exception of one regression where $\mathrm{M}$ averaged across all stages is employed and Holt and Laury (2002) variant variables are not included.

${ }^{42}$ This result is robust across all regressions in online Appendices $\mathrm{E}$ and $\mathrm{F}$.
} 
sense that they put less trust in other low status subjects (Result 1) and so engage in less discrimination (Result 4).

Three obvious qualifiers to our findings apply. First, our group identity manipulation is minimal, and, while this is a good first step to allow interpretability, it is possible that stronger group manipulations may be required to obtain larger or different asymmetries in behavioral results; we know that in other settings the strength of group manipulation does affect behavioral findings (e.g., Charness et al. 2007; Chen and Chen 2010). Nevertheless, it is striking how we find our minimal group status manipulation having an impact, and more so precisely because it is a minimal manipulation. Second, we cannot rule out that stronger effects of relative group size might follow from more unbalanced group manipulations. As noted in Footnotes 8 and 20, random matching was adopted to have the same probability to play with any other subject in the laboratory whether the co-participant belongs to the same or other group, and, as a by-product of random matching, we needed sufficiently large minority groups to ensure that subjects played with both insiders and outsiders and we maximized statistical power. However, more unbalanced groups are an obvious direction for future research. Third, since random matching was adopted, in the majority/minority treatments, minority group subjects are more frequently matched with majority group members. One might argue that minority subjects are deferential because of interacting more frequently with the majority group more than the minority group. However, on the one hand, the random matching ensured that the probability of re-matching with any given subject was precisely the same and so this strategy cannot be justified on the grounds of rational reputational effects; on the other hand, HHZ explicitly tested for the effect of greater frequency of interaction with a 'segregation' treatment where subjects played twice as frequently with insiders as with outsider, and did not find that the aggregate level of discrimination changed as a result of differences in the frequency ofinteraction. ${ }^{43}$

Another key finding of our experiment is that there is loss in psychological value from being either a low status 'outsider' or a member of a minority group. Nevertheless, Table 4 shows that in-group favoritism and positive perceived value are still present on average with low status subjects. This is a significant finding in the following sense. One potential criticism of our minimal status manipulation is that what we are really inducing is the perception of not being in any group. However, based on (say) the positive perceived value, it is clear that Not Blue subjects still perceive themselves as a group (if a less desirable, low status group) as opposed to perceive

\footnotetext{
${ }^{43}$ Table 2 of HHZ makes the point clearly (and is corroborated by the regressions in Table 3 of HHZ). A 'frequentist' interpretation would imply that there should be less discrimination in the baseline treatment (the 66 treatment in our paper and $C$ in HHZ) than in that with segregation. The reason is that in the baseline there is higher frequency of interaction with outsiders, and a lower frequency with insiders, than in the treatment with segregation. However, discrimination in the giving rate (i.e. giving rate towards insiders minus giving rate towards outsiders) was equal to 0.161 in the baseline and 0.141 in the segregation treatment; and discrimination in the return rate (i.e. return rate towards insiders minus return rate towards outsiders) was equal to 0.08 and 0.052 in the baseline and segregation treatments respectively. While the between-treatment differences are minimal (and obviously lacking significance), the point estimates are in the wrong direction relative to what the 'frequentist' interpretation would predict.
} 
themselves as belonging to no group. ${ }^{44}$ There are also real world examples, such as the traditional Japanese caste system discussed in the introduction, where being classified as outsiders to the high status group or groups is the defining feature of how the low status group is identified.

It is also interesting to compare these results to those from the psychological research, in relation to which the stylized finding is that, while not universally so, low status groups tend to display outgroup favoritism as opposed to the usual ingroup bias (e.g., Hinkle and Brown 1990; Jost and Burgess 2000; Hewstone et al. 2002). It is clear that the psychological research is right to suggest that low status group members value own group membership less, and are more deferential to high group status subjects as a result. Our study also replicates the psychological finding that low status subjects get lower satisfaction from group membership than on high status subjects (e.g., Ellemers et al. 1988, 1992; Sachdev and Bourhis 1987); so do minority subjects, with minorities generally being perceived more negatively than majorities (Lücken and Simon 2005; Seyranian et al. 2008).

There is a connection between the results on behavior and those on psychological value. Low status subjects appear to have low morale and this lower investment in own group identity leads to a reduction in trust towards other low status subjects. In relation to minority subjects, there is both low morale and a lower return rate towards other ingroup members. To put this in the organizational context referred to in the introduction, managers need to be aware of the potential unintended consequences for trust, trustworthiness and morale of creating status-based group partitions in an organization. There is the risk of causing low morale among low status-particularly if minority - workers, and, while high status subjects are not affected by discrimination, the overall impact on trust and trustworthiness for the organization is unlikely to be positive.

Because of overall negative discrimination, creating a polarized society in terms of emphasizing domestic (high status and majority) workers versus foreign workers, as it is common among a number for example of UK newspapers and politicians, erodes trust and trustworthiness, hence potentially leading to a more conflict prone society. If foreign workers indeed see themselves as low status, it may also reduce trust of foreign workers in other foreign workers, while reducing the negative effects in terms of trustworthiness with respect to domestic workers. The qualification on the foreign workers seeing themselves as low status is an obvious one, and is especially interesting to consider in the case of long standing status based social systems, such as the caste system in India or Japan. A common understanding of social status, as clearly identified in a caste system, ensures that a high caste agent does not suffer from the negative social capital implications of social group partitioning in the same way as an outcast. Future research is clearly useful to link our stylized artificial group experiment to a richer natural group setup, against which our work can act as a benchmark.

\footnotetext{
${ }^{44}$ For example, in all 10 status differential sessions Not Blue perceived values were equal to 0 (sign test $P=0.005$ in relation to both $\mathrm{M}$ and $\mathrm{Mb}$ ).
} 
One finding which is inconsistent with HHZ is that, in return rate regressions, higher perceived own group value is associated with less discrimination (Result 5). There is a countervailing effect for minority subjects (also as per Result 5) and Regression 24 in Table 8 shows that the two effects basically cancel each other for minority subjects. For subjects who are not in minorities, if our result were replicated, one possible interpretation of this would be that more stringent expectations of trust are associated with members of one's own group, leading to lower return rates for each given level of trust. Put it differently, insiders would feel more let down by any given level of trust from insiders 'like them' (Bacharach et al. 2007; Battigalli and Dufwenberg 2007), and as a result they would feel less incline to fulfill trust as a result. This could be seen as another side of what Bohnet et al. (2008) label betrayal aversion: if I strongly identify with a group and my higher expectations are not fulfilled, I am more likely to return less as a punishment. Obviously, however, future research needs to determine the extent to which these psychological valuation results are robust, let alone whether our interpretations have merit.

The fact that our results are robust to our experimenter demand effect instrument is at least suggestive evidence that such effects are not a problem in our experiment, or at least they are less of a problem than in most other experiments also given the subtlety of the social statue cue involved. This may not be surprising, since, in a different experiment on inter-group behavior, Turner (1975) reached a similar conclusion based on a detailed analysis of end of experiment subject reports showing that subjects did not see an experimentally 'appropriate' way to behave, and those that did, did not always conform to it. ${ }^{45}$ Nor is there reason to believe that having a market for groups may change group salience and so discrimination behavior as a result of an experimenter demand effect, since, as noted in an earlier footnote, HHZ ran a control treatment—closely mirroring our basic design-where there were groups but no market for groups and found no resulting difference.

There is a potential parallelism between our findings on minority subjects and our findings on low status subjects; in both cases, there is evidence of comparative unhappiness with one's own position and of deference towards (in the sense of less discrimination against) outsiders, though the latter operates differently for the two cases. It is too early to say whether, in a sense, subjects perceive being in a minority as being of low status. The different way in which a stronger psychological valuation operated with respect of minorities and status with respect to return rates would suggests that, as warned by psychologists (e.g., Hewstone et al. 2002), the analogy can only be drawn that far.

\footnotetext{
${ }^{45}$ Obviously, post-experiment debriefing has limitations (Zizzo 2010) and further research trying to control for the potential explanatory role of experimenter demand effects in affecting experimental research on intergroup behavior would be useful. In this sense, with our minimal group status manipulation and our EDE sensitivity measure, this paper is just a step towards doing so. One specific experimenter demand effect that we tested, following advice by a reviewer, was one where labeling the non-group members as 'outsiders' may lead to greater discrimination against them; in additional regressions, however, interacting a non-group members as 'outsiders' dummy with our EDE sensitivity dummy, we did not find this interaction negative, let alone statistically significantly so.
} 


\section{Conclusions}

We have presented an experiment which employed trust games to look at the impact of low group status and relative group size on trust, trustworthiness and discrimination. While the expected finding of negative discrimination found in HHZ was broadly supported, there are important ways in which group status and comparative group size made a difference. Low status subjects had comparatively low morale by being low status, as measured by own group valuation. They trusted less other low status subjects, implying a comparative deference towards high status subjects. Minority subjects had comparatively low morale by being in a minority. They were less trustworthy with respect to other minority subjects, implying a comparative deference towards majority subjects.

Stronger group identity led to higher discrimination in trust but, surprisingly, to being more unforgiving when it came to reciprocating trust. We conjecture that this may be due to subjects with strong group identity being more likely to feel let down by any lack of trust in them displayed by others in their group. Obviously, further research is needed to verify the robustness of our results, both in general and in relation to specific natural groups and sets of groups.

Acknowledgements We thank the University of East Anglia for financial support, three reviewers and participants to presentations in Amsterdam, Copenhagen, East Anglia, Nottingham and Oxford for useful advice. The usual disclaimer applies. The experimental instructions, and other appendices, can be found online at http://www.uea.ac.uk/ ec601/MinExpEAppendix2.pdf.

Open Access This article is distributed under the terms of the Creative Commons Attribution License which permits any use, distribution, and reproduction in any medium, provided the original author(s) and the source are credited.

\section{References}

Aberson, C. L., \& Howanski, L. M. (2002). Effects of self-esteem, status, and identification on two forms of ingroup bias. Current Research in Social Psychology, 7, 225-243.

Akerlof, G. A., \& Kranton, R. E. (2002). Economics and identity. The Quarterly Journal of Economics, $115,715-753$.

Alesina, A., Baqir, R., \& Easterly, W. (1999). Public goods and ethnic divisions. The Quarterly Journal of Economics, 114, 1243-1284.

Arifovic, J., Friesen, J., Ludwig, A., \& Wright, S. (2012). Ethnicity, identity and discrimination among children. Journal of Economic Psychology, 33, 1156-1169.

Bacharach, M., Guerra, G., \& Zizzo, D. (2007). The self-fulfilling property of trust: an experimental study. Theory and Decision, 63, 349-388.

Banerjee, A., Somanathan, R., \& Iyer, L. (2005). History, social divisions, and public goods in rural India. Journal of the European Economic Association, 3, 639-647.

Bateson, M., Nettle, D., \& Roberts, G. (2006). Cues of being watched enhance cooperation in a real-world setting. Biology Letters, 2, 412-414.

Battigalli, P., \& Dufwenberg, M. (2007). Guilt in games. The American Economic Review, 97, 170-176.

BBC (2007). Caste clouds India's high hopes. February 5. http://news.bbc.co.uk/1/hi/world/south_asia/ 6320413.stm.

Berg, J., Dickhaut, J., \& McCabe, K. (1995). Trust, reciprocity, and social history. Games and Economic Behavior, 10, 122-142.

Berger, J., Ho, B., \& Joshi, Y. (2011). Identity signaling with social capital: a model of symbolic consumption. SSRN discussion paper. 
Brewer, M. B. (1999). The psychology of prejudice: ingroup love and outgroup hate? Journal of Social Issues, 55, 429-444.

Brooks, E. (2010). Stop this state persecution of Roma. Guardian, August 18. http://www.guardian.co.uk/ commentisfree/libertycentral/2010/aug/18/persecution-roma-must-stop.

Bohnet, I., Greig, F., Herrmann, B., \& Zeckhauser, R. (2008). Betrayal aversion: evidence from Brazil, China, Oman, Switzerland, Turkey, and the United States. The American Economic Review, 98, 294 310.

Burnham, T., \& Hare, B. (2007). Engineering human cooperation. Human Nature, 18, 88-108.

Charness, G., Rigotti, L., \& Rustichini, A. (2007). Individual behavior and group membership. The American Economic Review, 97, 1340-1352.

Chen, R., \& Chen, Y. (2010). The Potential of social identity for equilibrium selection. Working paper, University of Michigan, Ann Arbor.

Chen, Y., \& Li, S. X. (2009). Group identity and social preferences. The American Economic Review, 99, 431-457.

Costello, K., \& Hodson, G. (2011). Social dominance-based threat reactions to immigrants in need of assistance. European Journal of Social Psychology, 41, 220-231.

Dunbar, R. (2006). We believe. New Scientist, 2536, 30-33.

Ellemers, N., Doosje, B., Van Knippenberg, A., \& Wilke, H. (1992). Status protection in high status minority groups. European Journal of Social Psychology, 22, 123-140.

Ellemers, N., Van Knippenberg, A., De Vries, N., \& Wilke, H. (1988). Social identification and permeability of group boundaries. European Journal of Social Psychology, 18, 497-513.

Engle-Warnick, J., \& Laszlo, S. (2006). Learning-by-doing in an ambiguous environment. CIRANO discussion paper 2006s-29, Montreal.

Falk, A., \& Fischbacher, U. (2001). Distributional consequences and intentions in a model of reciprocity. Annales d'Économie et de Statistique, 63-64, 7.

Fehr, E., \& Schmidt, K. M. (1999). A theory of fairness, competition, and cooperation. The Quarterly Journal of Economics, 114, 817-868.

Fehr, E., Fischbacher, U., von Rosenbladt, B., Schupp, J., \& Wagner, G. G. (2003). A nation-wide laboratory: examining trust and trustworthiness by integrating behavioral experiments into representative surveys. IEW working papers iewwp141, Institute for Empirical Research in Economics, University of Zurich.

Fehr, E., Hoff, K., \& Kshetramade, M. (2008). Spite and development. American Economic Review Papers and Proceedings, 98, 494-499.

Fershtman, C., \& Gneezy, U. (2001). Discrimination in a segmented society: an experimental approach. The Quarterly Journal of Economics, 116, 351-377.

Files, J. S., Casey, C. M., \& Oleson, K. C. (2010). Intergroup bias in children: development and persistence. European Journal of Social Psychology, 40, 671-678.

Fischbacher, U. (2007). Z-Tree: Zurich toolbox for ready-made economic experiments. Experimental Economics, 10, 171-178.

Glaeser, E. L., Laibson, D. I., Scheinkman, J. A., \& Soutter, C. L. (2000). Measuring trust. The Quarterly Journal of Economics, 115, 811-846.

Goette, L., Huffman, D., \& Meier, S. (2006). The impact of group membership on cooperation and norm enforcement: evidence using random assignment to real social groups. The American Economic Review, 96, 212-216.

Goette, L., Huffman, D., Meier, S., \& Sutter, M. (2012). Competition between organizational groups: its impact on altruistic and antisocial motivations. Management Science, 58, 948-960.

Guerra, G., \& Zizzo, D. Z. (2004). Trust responsiveness and beliefs. Journal of Economic Behavior \& Organization, 55, 25-30.

Haley, K. J., \& Fessler, D. M. T. (2005). Nobody's watching? Subtle cues affect generosity in an anonymous economic game. Evolution and Human Behavior, 26, 245-256.

Hargreaves Heap, S. P., \& Varoufakis, Y. (2002). Some experimental evidence on the evolution of discrimination, co-operation and perceptions of fairness. The Economic Journal, 112, 679-703.

Hargreaves Heap, S. P., \& Zizzo, D. J. (2009). The value of groups. The American Economic Review, 99, 295-323.

Harris, S., \& Brown, J. R. (1971). Self-esteem and racial preference in black children. In Proceedings of the 79th convention of the American psychological association (Vol. 6).

Hewstone, M., Rubin, M., \& Willis, H. (2002). Intergroup bias. Annual Review of Psychology, 575-605. 
Hinkle, S., \& Brown, R. (1990). Intergroup comparisons and social identity: some links and lacunae. In D. Abrams \& M. A. Hogg (Eds.), Social identity theory: constructive and critical advances (pp. 48-70). New York: Springer.

Hoffman, E., \& Spitzer, M. L. (1985). Entitlements, rights and fairness: an experimental examination of subjects' concepts of distributive justice. The Journal of Legal Studies, 14, 259-297.

Holt, C. A., \& Laury, S. K. (2002). Risk aversion and incentive effects. The American Economic Review, 92, 1644-1655.

Johnson, N. D., \& Mislin, A. (2008). Cultures of kindness: a meta-analysis of trust game experiments. Social science research network discussion paper.

Jost, J. T., \& Banaji, M. R. (1994). The role of stereotyping in system-justification and the production of false consciousness. British Journal of Social Psychology, 33, 1-27.

Jost, J. T., \& Burgess, D. (2000). Attitudinal ambivalence and the conflict between group and system justification motives in low status groups. Personality \& Social Psychology Bulletin, 26, 293-305.

Leonardelli, G. J., \& Brewer, M. B. (2001). Minority and majority discrimination: when and why. Journal of Experimental Social Psychology, 37, 468-485.

Levine, D. (1998). Modeling altruism and spitefulness in experiments. Review of Economic Dynamics, 1, 593-622.

Liebkind, K., Henning-Lindblom, A., \& Solheim, E. (2008). Group size, group status and trait valence as determinants of intergroup bias: stereotyping in Finland and Sweden. European Journal of Social Psychology, 38, 637-651.

Lücken, M., \& Simon, B. (2005). Cognitive and affective experiences of minority and majority members: the role of group size, status, and power. Journal of Experimental Social Psychology, 41, 396-413.

Milner, D. (1975). Children and race. Hardmondsworth: Penguin.

Montopoli, B. (2010). Obama criticizes "misguided" Arizona immigration bill. CBS News, April 23. http://www.cbsnews.com/8301-503544_162-20003274-503544.html.

Mulholland, H. (2010). Immigration minister vows to stop 'abuse' of student visa system. Guardian, August 2. http://www.guardian.co.uk/politics/2010/aug/02/review-student-visas-numbers-leap-third.

Sachdev, I., \& Bourhis, R. Y. (1985). Social categorization and power differentials in group relations. European Journal of Social Psychology, 15, 415-434.

Sachdev, I., \& Bourhis, R. Y. (1987). Status differentials and intergroup behavior. European Journal of Social Psychology, 17(3), 277-293.

Sachdev, I., \& Bourhis, R. Y. (1991). Power and status differentials in minority and majority group relations. European Journal of Social Psychology, 21, 1-24.

Seyranian, V., Atuel, H., \& Crano, W. D. (2008). Dimensions of majority and minority groups. Group Processes \& Intergroup Relations, 11, 21-37.

Sherif, M. (1967). Group conflict and co-operation. London: Routledge \& K. Paul.

Sidanius, J., \& Pratto, F. (1999). Social dominance: an intergroup theory of social hierarchy and oppression. New York: Cambridge University Press.

Sugimoto, Y. (2003). An introduction to Japanese society. Cambridge: Cambridge University Press.

Tajfel, H. (1970). Experiments in intergroup discrimination. Scientific American, 223, 96-102.

Tajfel, H., \& Turner, J. (2001). An integrative theory of intergroup conflict. In M. A. Hogg \& D. Abrams (Eds.), Intergroup relations (pp. 94-109). Philadelphia: Psychology Press.

Tan, J. H. W., \& Bolle, F. (2007). Team competition and the public goods game. Economics Letters, 96, 133-139.

Turner, J. C. (1975). Social comparison and social identity: some prospects for intergroup behavior. European Journal of Social Psychology, 5, 5-34.

Voci, A. (2006). Relevance of social categories, depersonalization and group processes: two field tests of self-categorization theory. European Journal of Social Psychology, 36, 73-90.

Zizzo, D. J. (2003). You are not in my boat: common fate and similarity attractors in bargaining settings. London: University of Oxford, Department of Economics.

Zizzo, D. J. (2010). Experimenter demand effects in economic experiments. Experimental Economics, 13, 75-98.

Zizzo, D. J., \& Fleming, P. (2011). Can experimental measures of sensitivity to social pressure predict public good contribution? Economics Letters, 111, 239-242. 